OPEN ACCESS

Edited by:

Tong Liu,

Tianjin Medical University, China

Reviewed by:

Ribo Tang,

Capital Medical University, China Hongliang Li,

University of Oklahoma Health Sciences Center, United States

*Correspondence:

Baopeng Tang

tangbaopeng111@163.com Xianhui Zhou zhouxhuiyf@163.com

tThese authors have contributed equally to this work

Specialty section:

This article was submitted to

Cardiac Rhythmology,

a section of the journal

Frontiers in Cardiovascular Medicine

Received: 18 March 2021

Accepted: 03 June 2021

Published: 01 July 2021

Citation:

Shang L, Zhang L, Guo Y, Sun $H$, Zhang $X$, Bo $Y$, Zhou $X$ and Tang $B$ (2021) A Review of Biomarkers for

Ischemic Stroke Evaluation in Patients With Non-valvular Atrial Fibrillation. Front. Cardiovasc. Med. 8:682538.

doi: 10.3389/fcvm.2021.682538

\section{A Review of Biomarkers for Ischemic Stroke Evaluation in Patients With Non-valvular Atrial Fibrillation}

\author{
Luxiang Shang ${ }^{1 \dagger}$, Ling Zhang ${ }^{2,3+}$, Yankai Guo ${ }^{2,3}$, Huaxin Sun ${ }^{2,3}$, Xiaoxue Zhang ${ }^{2,3}$, \\ Yakun $\mathrm{Bo}^{2,3}$, Xianhui Zhou ${ }^{2,3 *}$ and Baopeng Tang ${ }^{2,3 *}$ \\ ${ }^{1}$ Department of Cardiology, The First Affiliated Hospital of Shandong First Medical University \& Shandong Provincial \\ Qianfoshan Hospital, Shandong Medicine and Health Key Laboratory of Cardiac Electrophysiology and Arrhythmia, Jinan, \\ China, ${ }^{2}$ Xinjiang Key Laboratory of Cardiac Electrophysiology and Remodeling, The First Affiliated Hospital of Xinjiang \\ Medical University, Urumqi, China, ${ }^{3}$ Department of Pacing and Electrophysiology, The First Affiliated Hospital of Xinjiang \\ Medical University, Urumai, China
}

Atrial fibrillation (AF) is the most prevalent cardiac arrhythmia worldwide and results in a significantly increased ischemic stroke (IS) risk. IS risk stratification tools are widely being applied to guide anticoagulation treatment decisions and duration in patients with non-valvular AF (NVAF). The $\mathrm{CHA}_{2} \mathrm{DS}_{2}$-VASc score is largely validated and currently recommended by renowned guidelines. However, this score is heavily dependent on age, sex, and comorbidities, and exhibits only moderate predictive power. Finding effective and validated clinical biomarkers to assist in personalized IS risk evaluation has become one of the promising directions in the prevention and treatment of NVAF. A number of studies in recent years have explored differentially expressed biomarkers in NVAF patients with and without IS, and the potential role of various biomarkers for prediction or early diagnosis of IS in patients with NVAF. In this review, we describe the clinical application and utility of AF characteristics, cardiac imaging and electrocardiogram markers, arterial stiffness and atherosclerosis-related markers, circulating biomarkers, and novel genetic markers in IS diagnosis and management of patients with NVAF. We conclude that at present, there is no consensus understanding of a desirable biomarker for IS risk stratification in NVAF, and enrolling these biomarkers into extant models also remains challenging. Further prospective cohorts and trials are needed to integrate various clinical risk factors and biomarkers to optimize IS prediction in patients with NVAF. However, we believe that the growing insight into molecular mechanisms and in-depth understanding of existing and emerging biomarkers may further improve the IS risk identification and guide anticoagulation therapy in patients with NVAF.

Keywords: atrial fibrillation, non-valvular atrial fibrillation, ischemic stroke, biomarker, CHA2DS2-VASc score

\section{INTRODUCTION}

Atrial fibrillation (AF) is the most prevalent cardiac arrhythmia in clinical practice (1). Results from the famous Framingham Heart Study and Atherosclerosis Risk in Communities (ARIC) cohort showed that the lifetime risk to develop $\mathrm{AF}$ was up to one in three $(2,3)$. It is estimated that $\mathrm{AF}$ will affect $>8$ million people in America by 2050, and 18 million people in Europe by 2060 (1). Hence, 
AF poses a markedly increasing burden worldwide. Meanwhile, $\mathrm{AF}$ is a well-recognized risk factor for ischemic stroke (IS), heart failure (HF), cognitive decline, and is associated with substantial morbidity, disability, and mortality (4). The risk of IS among patients with $\mathrm{AF}$ is $\sim 5 \%$ per year and is up to 5 -fold higher than the general population (5). AF is reported to contribute to almost $15-20 \%$ of all stroke cases, and AF-related stroke has higher mortality and permanent disability than strokes from other etiologies (6). Therefore, IS prevention is the central pillar of AF management.

Oral anticoagulants effectively prevent IS and improve outcomes among patients with AF (7). However, prior to anticoagulation, stroke risk assessment is the first and the most vital step to maximize the benefits of anticoagulant drugs. Clinicians should identify patients at high-risk for IS, who will benefit in the first line from anticoagulation, or rather determine patients at low-risk of IS, in whom anticoagulation may not be warranted. In current clinical practice, the $\mathrm{CHA}_{2} \mathrm{DS}_{2}$-VASc score is recommended by the most influential guidelines as the primary means of stratifying patients with non-valvular AF (NVAF) (810). The major advantage of the $\mathrm{CHA}_{2} \mathrm{DS}_{2}$-VASc score is its perspicuity and simplicity of use, as it is a clinical risk-factorbased prediction score. However, it also has several drawbacks, such as widely ranged stroke rates of non-anticoagulated AF patients in different populations, and a limited predictive ability of stroke events $(11,12)$.

In recent years, biological markers (biomarkers) have been constituted a very powerful tool in the early diagnosis, risk stratification, prognosis prediction, and guiding therapy in many cardiovascular diseases $(13,14)$. According to the definition of the Biomarkers Definitions Working Group, "any characteristic that can be objectively measured and evaluated as an indicator of normal biological processes, pathogenic processes, or pharmacologic responses to a therapeutic intervention" is belonged to a biomarker (15). With the advancements in medicine, the contents of biomarkers have also continuously extended. A number of studies have explored differentially expressed biomarkers in NVAF patients with and without IS, and the potential role of various biomarkers for the prediction or early diagnosis of IS in patients with NVAF. Some previous publications have also summarized these biomarkers (16-21). However, in recent years, research into the possible biomarkers capable of predicting the IS events in patients with NVAF is constantly growing. Hence, our present updated review will focus on the current status of clinical biomarkers beyond the $\mathrm{CHA}_{2} \mathrm{DS}_{2}$-VASc score for the assessment of IS in patients with NVAF, which might provide a basis for the future perspectives of clinical application.

\section{$\mathrm{CHA}_{2} \mathrm{DS}_{2}$-VASc SCORE AND ITS LIMITATIONS}

In 2001, Gage et al. created the $\mathrm{CHADS}_{2}$ index that included five variables: congestive HF, hypertension, age, diabetes, and stroke, for a maximum of 6 points, and has been well-validated in the National Registry of AF, which showed high prediction performance (c-statistic of 0.82) (22). However, later studies indicated that a $\mathrm{CHADS}_{2}$ score of $0-1$ has poor identification of NVAF patients at truly low risk of IS $(23,24)$. Moreover, this score ignored several potential clinical risk factors for IS. Thus, in 2010, the $\mathrm{CHA}_{2} \mathrm{DS}_{2}$-VASc score was developed by restratifying the risk of IS based on the $\mathrm{CHADS}_{2}$ score, which incorporated three additional components: vascular disease, age 65-74, and female sex (25). A national prospective study has confirmed that the predictive ability for low risk of IS with the $\mathrm{CHA}_{2} \mathrm{DS}_{2}$-VASc score is significantly superior to the $\mathrm{CHADS}_{2}$ score, which provides more reliable guidance to determine whether or not anticoagulation treatment is required in patients with NVAF (23). The above two scores exhibited similar predictabilities in meta-analytic data, but $\mathrm{CHA}_{2} \mathrm{DS}_{2}$ VASc score had the important advantage of identifying extremely low-risk patients (26). Altogether, the $\mathrm{CHA}_{2} \mathrm{DS}_{2}$-VASc score is currently considered as a core risk stratification model for IS assessment in patients with NVAF.

Despite the simplicity and practicality, certain limitations exist in the $\mathrm{CHA}_{2} \mathrm{DS}_{2}$-VASc score. First, the contribution of the individual component to the risk of IS in patients with NVAF is unequal, but most components carry equal weight, and only two risk factors, age and prior stroke/transient ischemic attack (TIA), are assigned with different points $(27,28)$. Second, cardiovascular complications screening varies in practice by country and region. For example, ankle-brachial index (ABI), an indicator of peripheral arterial disease (PAD), is not routinely assessed in developing countries, which might potentially lead to an underestimation of the overall IS risk. Third, racial/ethnic differences may exist in IS risk prediction in NVAF, and the $\mathrm{CHA}_{2} \mathrm{DS}_{2}$-VASc score may not be validated in an ethnically diverse population (29). For example, the determination of the age threshold of IS risk assessment may vary with different populations (30). Forth, several other identified risk factors or biomarkers not included in the score, which lead to a suboptimal predictive performance in selected populations (e.g., patients with renal insufficiency) (31). Moreover, evidence from a recent systematic review shows that this score has not ideal predictive power (c-statistic of 0.6-0.7) (12). It is, thus, essential to improve the prediction accuracy of this model.

\section{OTHER RISK STRATIFICATION MODELS}

Several recent studies have attempted to refine the $\mathrm{CHA}_{2} \mathrm{DS}_{2}$ VASc score system. Maheshwari et al. found that abnormal Pwave axis (aPWI) can predict the occurrence of IS independent of $\mathrm{CHA}_{2} \mathrm{DS}_{2}$-VASc variables, and proposed $\mathrm{P}_{2}-\mathrm{CHA}_{2} \mathrm{DS}_{2}$ VASc score to assess the risk of AF-related stroke, in which aPWI was scored with 2 points (32). A study from China indicated that urine albumin was an independent predictor of thromboembolism (TE) events for NVAF patients, and the new $\mathrm{CHA}_{2} \mathrm{DS}_{2}$-VASc-UA 2 score system showed better performance in predicting TE events compared with the $\mathrm{CHA}_{2} \mathrm{DS}_{2}$-VASc score (33). Similarly, an analysis of the national health insurance database of more than 460,000 AF patients shows that the addition of African-American race (1 point) to $\mathrm{CHA}_{2} \mathrm{DS}_{2}$-VASc 
score $\left(\mathrm{CHA}_{2} \mathrm{DS}_{2}\right.$-VASc-R score) significantly improved stroke prediction (34). In a recent study analyzing Korean NVAF populations, chronic kidney disease (CKD) but not female sex is an independent predictor of TE events (35). The authors proposed a $\mathrm{CHA}_{2} \mathrm{DS}_{2}$-VAK score in which "S" ex "c"ategory was replaced by "K"idney disease, the new score system enhanced discrimination of low to intermediate TE risk in NVAF patients (35). In another Asian study, a modified $\mathrm{mCHA}_{2} \mathrm{DS}_{2}$-VASc score, which assigned one point for patients aged 50-74 years, demonstrated a better predictive performance than the $\mathrm{CHA}_{2} \mathrm{DS}_{2}$-VASc in Taiwan AF population (36). Patients with a $\mathrm{mCHA}_{2} \mathrm{DS}_{2}$-VASc score of 1 (males) or 2 (females) obtained positive net clinical payoffs from anticoagulation therapy (36).

Furthermore, investigators are also proposing new prognostic models, such as ATRIA score, GARFIELD-AF model, and ABC stroke score (Table 1). Similar to the $\mathrm{CHA}_{2} \mathrm{DS}_{2}$-VASc score, these models all incorporate age and common clinical risk factors of IS. The ATRIA score takes into account the interaction between age and previous stroke (37). The GARFIELD-AF model is composed of more than 30 clinical risk factors (38). The ABC stroke risk score is a biomarkers-based nomogram, which include age, N-terminal prohormone of brain natriuretic peptide (NTproBNP), cardiac troponin I (cTnI), and prior stroke/TIA (39). Therefore, the calculation of these scores is complicated, making it impractical for clinical use. Moreover, a recently published systematic review, which summarized current risk stratification tools for IS prediction in patients with NVAF, did not show a better prediction role for the above scores in improving the ability of IS events compared with $\mathrm{CHADS}_{2}$ and $\mathrm{CHA}_{2} \mathrm{DS}_{2}$-VASc score (12). Taken together, despite the limitations of the $\mathrm{CHA}_{2} \mathrm{DS}_{2}$ VASc score, no strong evidence has been able to show that these novel or modified risk scores can replace it.

\section{CLINICAL BIOMARKERS BEYOND THE $\mathrm{CHA}_{2} \mathrm{DS}_{2}$-VASC SCORE FOR IS EVALUATION IN NVAF}

While IS risk prediction scores have been heavily weighted by well-established clinical factors, findings from randomized controlled trials (RCTs) and community-based cohorts showed that various biomarkers can improve predictive accuracy and risk assessment. Numerous studies have examined the utility of AF characteristics, cardiac imaging and electrocardiogram (ECG) markers, atherosclerosis-related markers, circulating biomarkers, and novel genetic markers (Figure 1) in IS prediction in patients with NVAF. These biomarkers, whether new or old, may enhance our understanding of the pathophysiology of AF-related IS and help us to find new therapeutic targets.

\section{AF CHARACTERISTICS}

The type, duration, and burden of AF are the most frequent clinical characteristics assessed by clinicians. AF has been conventionally categorized into "valvular" or "non-valvular" on the basis of the presence or absence of valvular heart disease. Besides, the types of AF can be classified as first diagnosed, paroxysmal, persistent, long-standing persistent, and permanent AF in light of the presentation, duration, and spontaneous termination of AF episodes. The secondary analysis of several RCTs which examined the clinical efficacy of novel oral anticoagulants or aspirin in $\mathrm{AF}$ patients demonstrated that persistent and permanent AF increased the risk of IS compared to paroxysmal AF in patients taking anticoagulation therapy, as well as patients taking antiplatelet therapy (4043). Similarly, in one Japanese cohort study, a lower incidence of stroke/systemic embolism was observed in paroxysmal AF compared with sustained AF regardless of oral anticoagulant uses (44). A meta-analysis of 12 studies containing 99,996 patients showed that non-paroxysmal AF is associated with an increase in TE events [hazard ratio $(\mathrm{HR})=1.384,95 \%$ confidence intervals (CI):1.191-1.608, $P<0.001$ ] compared with paroxysmal AF, and in subgroup analyses, this difference was present for both patients on oral anticoagulants and not on oral anticoagulants (45).

Although ECG and 24-h Holter are commonly applied in patients with $\mathrm{AF}$, it still requires a longer period of continuous monitoring to obtain AF burden and duration. Current studies that assess the burden of AF and stroke risk are mostly based on patients with cardiovascular implantable electronic device (CIED) implantation. Atrial high rate episodes (AHREs) were exactly described as the unknown AF with a fast atrial episode (>180 bpm) recorded on CIED for at least $5 \mathrm{~min}$ (46). Epidemiological data reported the incidence of AHRE reached 25-35\% during 2-year follow-up in patients without a natural history of AF (47). Current evidence supported the elevated AHRE burdens increased the risk of adverse cardiovascular prognoses such as myocardial infarction, HF, and ventricular arrhythmia (48). Additionally, the association was being drawn between AHRE and increased stroke risk by a growing number of clinical trials. Early in 2003, the MOST (Mode Selection Trial) investigators prospectively evaluated the association between AHREs and clinical outcomes in sinus node dysfunction patients with pacemaker therapy. After the adjustments of prognostic and baseline variables, AHRE was reported as the independent risk factor of death or non-fatal stroke (HR $=2.79$, 95\% CI:1.51$5.15, P=0.0092$ ) by Cox proportional hazards analysis (49). The ASSERT trial on the larger sample size detected the AHREs in the population without diagnostic $\operatorname{AF}(n=2,580)$ for 3 months after ICD implantation. Such subclinical AF, a confirmed predictor of stroke, contributed to the increased risk of IS or systemic embolism $(\mathrm{HR}=2.49,95 \% \mathrm{CI}: 1.28-4.85, P=0.008)$ (50). Meanwhile, the correlation between asymptomatic AF and high TE risk has been illustrated by the EORP-AF Pilot General Registry (51). Compared with healthy controls, asymptomatic AF patients potentially progressed to permanent AF, and may lead to higher systemic ischemic events $(52,53)$. A proof-of-concept study found that machine-learned signatures of AF burden could provide prognostic information on the near-term risk of stroke in patients with CIED (54). However, a recent cohort study that included 384 CIED implanted patients without anticoagulation showed that the burden and duration of AF were not associated with IS/TIA, and only the $\mathrm{CHA}_{2} \mathrm{DS}_{2}$-VASc score can predict IS/TIA (55). The inconsistency in the aforementioned results may 
TABLE 1 | Influential IS risk stratification models/scores for NVAF.

\begin{tabular}{|c|c|c|c|c|}
\hline Model/Score & Components & Points & Range of stroke risk stratification & $\begin{array}{l}\text { Validation } \\
\text { studies }\end{array}$ \\
\hline $\mathrm{CHADS}_{2}$ score & Heart failure, hypertension, age, diabetes, stroke & 0 to 6 & $\begin{array}{l}\text { Low (0 point), moderate ( } 1 \text { point), } \\
\text { high ( } \geq 2 \text { points) }\end{array}$ & Yes \\
\hline $\begin{array}{l}\mathrm{CHA}_{2} \mathrm{DS}_{2}-\mathrm{VASc} \\
\text { score }\end{array}$ & $\begin{array}{l}\text { Heart failure, hypertension, age } \geq 75 \text {, diabetes, stroke, } \\
\text { vascular disease, age } 65-74 \text {, female sex }\end{array}$ & 0 to 9 & $\begin{array}{l}\text { Low (0 point), moderate ( } 1 \text { point), } \\
\text { high ( } \geq 2 \text { points) }\end{array}$ & Yes \\
\hline ATRIA score & $\begin{array}{l}\text { Age, prior stroke, female sex, diabetes, heart failure, } \\
\text { hypertension, proteinuria, eGFR }<45 \text { or ESRD }\end{array}$ & 0 to 15 & $\begin{array}{l}\text { Low (0-5 points), moderate ( } 6 \text { points), } \\
\text { high ( } 7-15 \text { points) }\end{array}$ & Yes \\
\hline $\begin{array}{l}\text { GARFIELD-AF } \\
\text { model }\end{array}$ & $\begin{array}{l}\text { Age, pulse, systolic blood pressure, vascular disease, history } \\
\text { of bleeding, heart failure, renal disease, use of } O A C^{\star}\end{array}$ & $\begin{array}{l}\text { Machine } \\
\text { learning } \\
\text { model }\end{array}$ & - & Yes \\
\hline ABC stroke score & Age, prior stroke/transient ischemic attack, NT-proBNP, cTnl & Nomogram & - & Yes \\
\hline
\end{tabular}

*Components of the simplified GARFIELD-AF risk model.

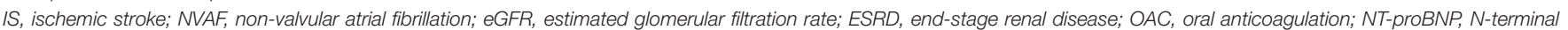
prohormone of brain natriuretic peptide; cTnl, cardiac troponin I.

be caused by the difficult screening of subclinical ischemic brain lesions (IBLs), which results in an underestimated embolic rate. A Spanish research group prospectively assessed the relationship of AHRE and IBLs through the computed tomography scan in patients with CIED implantations, and results showed that AHRE was an independent predictor for silent IBL both in the overall population and in patients without a history of AF or stroke (56). Similar results were observed in patients with cardiac resynchronization therapy (57). However, there is no sufficient evidence to reveal the distinct temporal relevance between AHRE and subsequent events. As shown in TRENDS study, an AHRE episode is able to be recorded before, during, or after the stroke event (58). Based on current cognition, whether the AHRE performs a cause or merely a biomarker of TE should be interpreted more prudently. In addition, with the development of science and technology, the increasing using of wearable devices and apps in daily life and clinical practice may be useful and convenient to quantify AF burden (59). We consider that more research is needed in the future to explore the role of wearables-detected AF burden in evaluating IS events.

\section{CARDIAC IMAGING AND ECG BIOMARKERS}

According to Virchow's triad, there are three pivotal factors to venous thrombosis: vascular damage, blood stasis, and hypercoagulability. With the progression of $\mathrm{AF}$, progressive atrial dilatation, endocardial denudation, and oedematous or fibroelastic infiltration of the extracellular matrix will lead to abnormal blood flow patterns through the atrium and the formation of intra-atrial thrombus (60). Therefore, using parameters that reflect cardiac structural and functional remodeling to predict the risk stratification of $\mathrm{TE}$ events in NVAF is very meaningful. In fact, a large number of studies have investigated the role of cardiac, especially atrial structure, function, electrocardiography, and cardiac circulating biomarkers in AF-related IS.

\section{Left Atrial Appendage (LAA) Structure and Function}

LAA is an embryological remnant of the primordial left atrium (LA). As early as two decades ago, LAA was reported to be closely related to atrial thrombus formation in NVAF patients because of its hooked morphology and "low flow state" (61). In 2012, Di Biase et al. (62) firstly divided LAA morphology into four types: Chicken wing, Cactus, Windsock, and Cauliflower, and reported that NVAF patients with non-Chicken Wing (CW) LAA morphologies were more likely to occur TE events than $\mathrm{CW}$ patients after controlling for comorbidities and $\mathrm{CHADS}_{2}$ score. A later meta-analysis included in 12 studies showed that the risk of cerebrovascular accident in AF patients with CW morphology was reduced by $41 \%$ relative to non-CW patients (63). However, this subjective classification of LAA morphology is not well-quantifiable and can be widely influenced by clinicians and reviewers. In one study conducted in Fuwai Hospital, the consensus of LAA morphology was only reached in $28.9 \%$ among three experienced reviewers (64). A retrospective study revealed that the classification of with or without clearly lobulated structure of LAA, a relatively concise classification strategy, was independently associated with LAA thrombosis in NVAF patients $(\mathrm{OR}=4.216,95 \% \mathrm{CI}: 1.825-9.740, P=0.001)$ (65). Several recent studies investigated the role of quantitative assessments of LAA, such as the angle bend from the proximal/middle portion of the LAA (66) and statistical shape analysis of LAA (67) in predicting stroke. Nevertheless, large-scale validation is needed to further verify these preliminary findings. Additionally, Zhao et al. (68) showed that higher position of LAA orifice had a strong relationship with thrombus formation after adjusting for confounding factors in AF patients, which was consisting with Nedios et al. (69), who reported that higher position of the superior LAA-takeoff in NVAF patients was paralleled with increasing TE events after catheter ablation. Furthermore, the Stroke Prevention in Atrial Fibrillation (SPAF-III) Study trial revealed that low LAA flow velocity $(<0.2 \mathrm{~m} / \mathrm{s})$, reflecting the systolic function of LAA, was associated with TE events in AF patients (70). Similar results were shown in a Korean study, in which increased orifice size and decreased flow velocity of LAA 


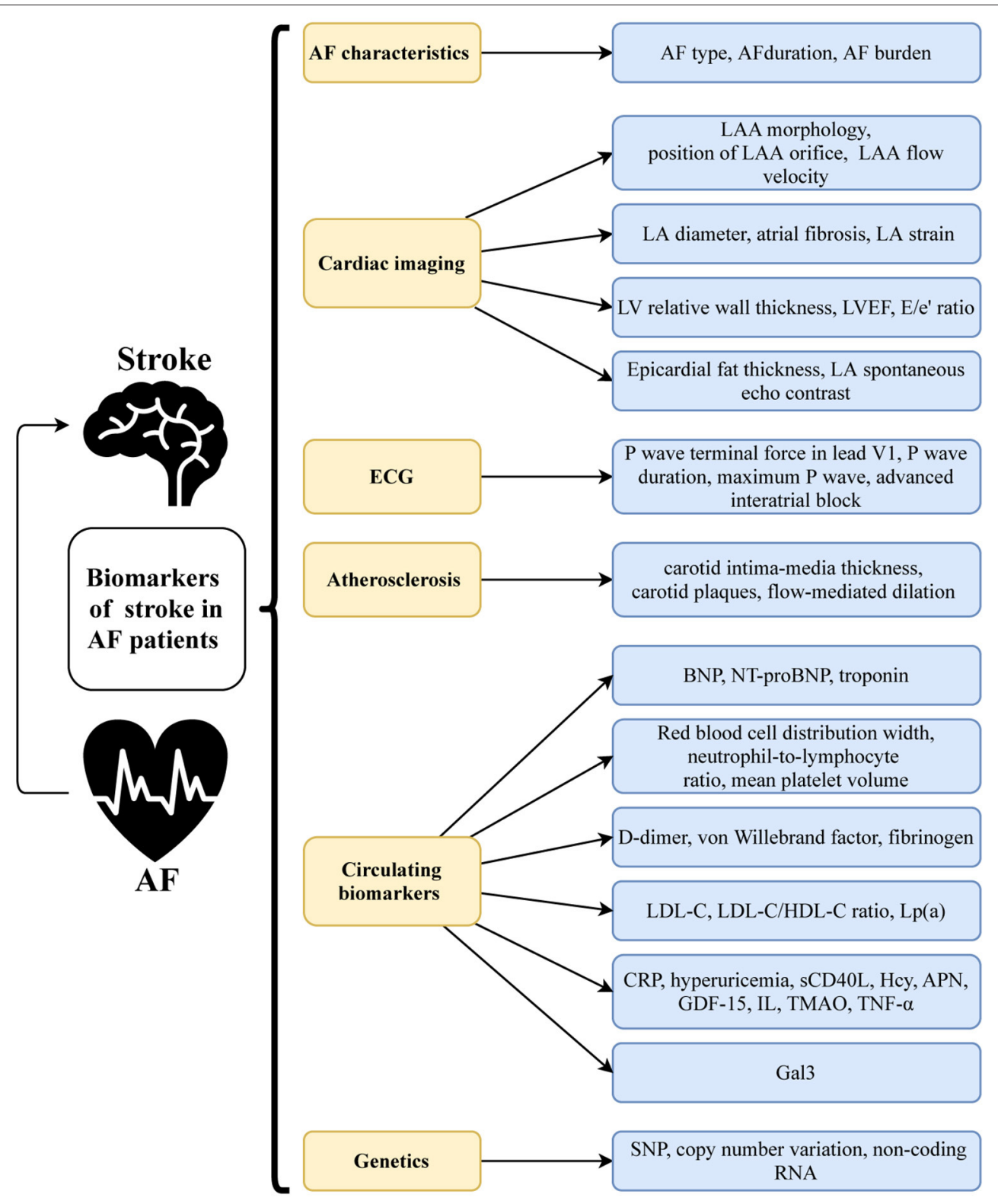

FIGURE 1 | Classification of biomarkers in AF-related stroke.

were related to IS risk in patients with NVAF (71). In a word, the structural and functional characteristics of LAA contributed to the assessment of IS risk in NVAF patients.

\section{LA Structure and Function}

The structure and function of LA could also assist in IS prediction in patients with NVAF $(72,73)$. In Fushimi AF Registry, a large community-based cohort study of Japanese NVAF patients, larger LA diameter (LAD) was a strong predictor of stroke/TE whether oral anticoagulant was used or not $(\mathrm{HR}=1.74$, 95\% CI: $1.25-$ 2.42, $P<0.01$ ) (74). This was paralleled with the result from the Framingham Heart Study (75), in which LA enlargement remained a significant predictor of stroke in male AF patients.
Paciaroni et al. (76) reported that severe LA dilation (defined by $\mathrm{LAD} \geq 5.0 \mathrm{~cm} / \mathrm{m}^{2}$ or $\mathrm{LAVi} \geq 40 \mathrm{ml} / \mathrm{m}^{2}$ ) was associated with the incidence of TE events $(\mathrm{OR}=2.05,95 \% \mathrm{CI}$ : $1.08-2.87, P=$ 0.027). Additionally, the functional status of LA also needs to pay more attention. It has been established that atrial fibrosis, which could be assessed with late gadolinium enhancement (LGE) on cardiac magnetic resonance imaging (MRI), was independently associated with the higher risk of TE events $(77,78)$. In a mean of 7.9 years follow-up study of 1,361 first diagnosis of AF patients, P-wave to $\mathrm{A}^{\prime}$ duration on tissue Doppler imaging, reflecting total atrial conduction time, was independently associated with IS risk in a fully-adjusted model including $\mathrm{CHA}_{2} \mathrm{DS}_{2}$-VASc score, age, and anticoagulant use (79). Furthermore, previous studies have 
documented that LA strain was also associated with LA fibrosis, and the independent relationship between the reduced LA strain, strain rate, and IS were subsequently certificated (80-82).

\section{Left Ventricular (LV) Structure and Function}

Parameters of LV structure have shown closely related to stroke events in AF patients, the underlying pathophysiologic mechanism lies in that elevated LV filling pressure would lead to LV hypertrophy and subsequent LA dilation (73). In the ARAPACIS Study, the prevalence of LV hypertrophy in patients with NVAF is higher, which is consistent with the higher risk of TE risk in these patients (83). Meantime, in a large communitybased prospective study, Tezuka et al. (84) manifested that after adjustment for various potential confounders, high LV relative wall thickness (RWT) was independently associated IS in NVAF patients $(\mathrm{HR}=1.81,95 \% \mathrm{CI}: 1.34-2.47, P<0.01)$, indicating the vital role of LV morphology in contributing to TE. Additionally, LV systolic function categorized by LV ejection fraction (LVEF) was thought of as a key TE event predictor in NVAF. In fact, as the most important diagnostic indicator of HF, LVEF has already been included in the $\mathrm{CHA}_{2} \mathrm{DS}_{2}$-VASc score. In 1992, Asinger et al. (85) found that LV dysfunction was associated with TE events in 568 AF patients (RR $=2.0,95 \% \mathrm{CI}: 1.0-4.0$, $P<0.05$ ). Result from 3 RCTs including 1,066 NVAF patients also showed that moderate to severe LV systolic dysfunction was a strong independent predictor of stroke $(\mathrm{RR}=2.5,95 \%$ CI: $1.5-4.4, P<0.01)$ (86). As a more reliable and stable index of LV dysfunction, we speculate that LV strain could provide a significant advantage in predicting IS compared with LVEF. However, as far as we know, there was no current study certificated that the LV strain could be used as a predictor of stroke in NVAF. Besides, previous studies have documented the evident relationship between chronic LV diastolic dysfunction and LA enlargement, promoted the AF occurrence and thrombi formation (73). Among LV diastolic parameters, E/e' ratio had an independent association with stroke in NVAF patients (OR $=1.21,95 \% \mathrm{CI}: 1.08-1.37, P=0.002)$ (87). Therefore, structural and functional parameters of LV also play an important role in predicting IS in patients with NVAF.

\section{Other Echocardiographic Indicators}

In addition to the above markers, other echocardiographic indicators also deserve considerable attention. In a matched cross-sectional study, the role of epicardial fat thickness in AF patients with and without acute IS was analyzed, and higher epicardial fat thickness (OR $=7.356,95 \% \mathrm{CI}$ : 3.880-13.947, $P$ $<0.0001$ ) independently predicted acute IS (88). Early studies demonstrated that LA spontaneous echo contrast (LASEC), a frequent finding on transesophageal echocardiography, was thought to a marker of the hypercoagulable state (89). A prospective cohort study showed that NVAF patients with IS had higher grades and video intensity value of LASEC compared with patients without IS, and the video intensity value of LASEC had a better predictive performance of IS in NVAF patients than LA thrombus, $\mathrm{CHADS}_{2}$ score, and $\mathrm{CHA}_{2} \mathrm{DS}_{2}$-VASc score (90).

\section{ECG Markers}

The $\mathrm{P}$ wave results from electric activity in the atrium and is an indicator of atrial depolarization (91). Thus, $\mathrm{P}$ wave indices could be used to evaluate the LA abnormalities, which might further be associated with increased risk of IS in AF patients. A recent systematic review reported that several common $\mathrm{P}$ wave indices, including $\mathrm{P}$ wave terminal force in lead V1, $\mathrm{P}$ wave duration, and maximum $\mathrm{P}$ wave area were predictors of IS (92). As earlier mentioned, an abnormal P-wave axis was associated with increased IS risk independent of $\mathrm{CHA}_{2} \mathrm{DS}_{2}$-VASc score in AF patients (32). In addition, some small sample studies have shown that advanced interatrial block, diagnosed upon the duration of the $\mathrm{P}$ wave and morphology in limb lead ECG, could serve as a marker of atrial electromechanical dysfunction and a surrogate for LA strain reduction, and might act as a predictor of IS in AF patients $(93,94)$.

In summary, parameters of cardiac MRI, echocardiography, and ECG could reflect the atrial and ventricular structure and function and could be used as risk predictors of IS in NVAF. Moreover, in the last years, innovations in multimodality imaging can offer a comprehensive evaluation of cardiac remodeling, which we believe could be further used for accurate IS prediction in AF patients (95).

\section{ARTERIAL STIFFNESS AND ATHEROSCLEROSIS-RELATED MARKERS}

Atherosclerosis a well-recognized risk factor for IS in the general population. Vascular diseases, including a history of myocardial infarction, aortic plaque, and $\mathrm{PAD}$, is a component of the $\mathrm{CHA}_{2} \mathrm{DS}_{2}$-VASc score. However, as previously mentioned, PAD and aortic plaques examinations are not routinely performed for AF patients in many instances. Therefore, many studies have explored the predictive role of other arteriosclerosisrelated indicators such as carotid intima-media thickness (cIMT), carotid plaques, and flow-mediated dilation (FMD) with IS in NVAF.

Our previous hospital-based study showed that carotid plaque was detected in more than half of patients with NVAF (96). In fact, a growing number of studies across the globe have shown that carotid plaque is more common in patients with AF than in those without AF (97). Result from ARAPACIS study showed that the combination of vascular diseases and carotid plaque was independently associated with stroke in patients with NVAF (HR $=1.78,95 \% \mathrm{CI}: 1.05-3.01, P=0.0318)$ (98). Similarly, two studies from Korea (99) and the USA (100) both demonstrated that the addition of cIMT and carotid plaque in the $\mathrm{CHA}_{2} \mathrm{DS}_{2}$-VASc score can better predict the occurrence of IS in patients with AF. In addition, a case-control study suggested that the stability of carotid plaques was also associated with IS in patients with NVAF (101). A recently published systematic review identified available data and confirmed an association of carotid atherosclerosis with the risk of IS and TIA in patients with AF (102). In a 2-year follow-up study, low FMD was associated with an increased composite endpoint for cardiovascular events including IS in NVAF patients (103). It is noteworthy that 
evidence from a meta-analysis revealed that the use of statins, the most common clinically anti-atherosclerotic agent, reduces mortality in AF patients, which might, on the other hand, illustrate that atherosclerosis has a detrimental role contributing to IS in patients with AF (104). In general, given its simplicity and stability, we believe that carotid plaque is a promising marker for improving classification in $\mathrm{CHA}_{2} \mathrm{DS}_{2}$-VASc score in NVAF patients.

\section{CIRCULATING BIOMARKERS}

\section{Cardiac Biomarkers}

There is a broad consensus that elevated B-type natriuretic peptide (BNP) and NT-proBNP are the hallmarks of HF (105). BNP is mainly produced by cardiac myocytes as a response to increased end-diastolic pressure and/or volume expansion, and then enzymatically cleaved to the NT-proBNP (106). Recent studies suggested that BNP and NT-proBNP might also have the effect of predicting stroke in AF patients. One possible reason is that the increased pressure of atrial myocytes can lead to the increased secretion of BNP, and thus reflecting atrial dysfunction (16). An early small-sample research indicated that elevated BNP level was significantly associated with TE events in AF patients treated with warfarin (107), since increased levels of BNP was observed at the acute stage of IS (108) and in patients with a history of TE or echocardiographic evidence of thrombus (109) of NVAF patients. Post-hoc analyses of ARISTOTLE trial (110), RE-LY trial (111), and ENGAGE AF-TIMI 48 trial (112) similarly showed that NT-proBNP was independently associated with the increased risk of IS, and adding NT-proBNP to the $\mathrm{CHA}_{2} \mathrm{DS}_{2}$ VASc score could improve C-statistics. Similarly, a single-center study showed that incorporating NT-proBNP into the $\mathrm{CHA}_{2} \mathrm{DS}_{2}$ VASc score increased the ability of IS/systemic embolism risk prediction in anticoagulated patients with AF by $17 \%$ (113). Result of the Hokuriku-Plus AF Registry illustrated that high levels of BNP were also increased the risk of TE events in NVAF patients (114), which was corresponded with the findings of Paulin et al. (115). Evidence from a multicenter, prospective observational study (Fushimi AF Registry) showed that BNP was associated with IS and TE events in patients with AF without $\mathrm{HF}$, and the addition of $\mathrm{BNP}$ into $\mathrm{CHA}_{2} \mathrm{DS}_{2}$-VASc score as a new risk prediction model can better predict IS risk (116). In addition, high levels of BNP can be used as a predictive marker for recurrent IS in IS survivors with AF (117). Moreover, BNP can also be used as an etiological diagnosis indicator of acute IS in patients with AF. Sakamoto et al. (118) reported that low levels of BNP $(<130 \mathrm{pg} / \mathrm{mL})$ were associated with non-cardiogenic IS, while high levels of BNP were associated with cardiogenic IS, which may be due to the fact that BNP could promote intracardiac thrombosis.

Troponin is a marker of myocardial injury and is widely used in the diagnosis and prognosis of acute coronary syndrome (105). As the most widely applied biomarker in cardiovascular disease, emerging evidence suggested that troponin could also predict stroke in patients with AF. In a retrospective study of 199 NVAF patients, elevated hs-cTnI was independently associated with abnormal anatomy of the LA, defined as LAA flow velocity
$<20 \mathrm{~cm} / \mathrm{s}$ or dense spontaneous echo contrast, and the incidence of IS increases with higher cTnI levels (119). Similar to NTproBNP, the post-hoc analyses of ARISTOTLE trial (120), RE-LY trial (111), and ENGAGE AF-TIMI 48 trial (112) also indicated a positive association between $\mathrm{cTnI} / \mathrm{cTnT}$ level and risk of TE/IS, and integrating troponin to the $\mathrm{CHA}_{2} \mathrm{DS}_{2}$-VASc score could improve C-statistics. In a real-world cohort study, after adjusting for $\mathrm{CHA}_{2} \mathrm{DS}_{2}$-VASc score, a high level of cTnT $(\geq 8.04 \mathrm{ng} / \mathrm{L})$ was shown to be associated with IS/TIA in patients with AF (HR = 2.44, 95\%CI:1.13-5.26, $P=0.023$ ) (121). In a study validating the performance of $\mathrm{ABC}$ risk score, $\mathrm{CTnT}$ has also been shown to be correlated with IS/systemic embolism in patients with AF (122). A recent meta-analysis which focused on the correlation between hs-cTnT and risk of stroke showed that the HR value of IS in AF patients with a high level of hs-cTn was 1.95 (95\% CI: 1.29-2.62), suggesting that hs-cTn could be used as a marker of IS risk stratification in AF patients (123).

To sum up, the BNP, NT-proBNP, and cTn are shown to be effective to improve risk stratification in addition to the current $\mathrm{CHA}_{2} \mathrm{DS}_{2}$-VASc score. They are widely used and readily accessible in clinics, and are easy to popularize in daily clinical practice. Further, the dynamic evolution of each cardiac marker must not be overlooked. In a very recent result from ENGAGE AF-TIMI 48 trial, there were quite a large number of AF patients who experienced dynamic changes of NT-proBNP and hs-cTnT in the follow-up, and upward changes in these markers were associated with increased risk of IS/systemic TE (124). This might increase the burden of these markers on clinical application.

\section{Markers of Routine Blood Test}

The complete blood cell count is one of the most frequently ordered laboratory tests in clinical practice. Previous findings suggested that several parameters in routine blood tests, such as red blood cell distribution width (RDW), neutrophil-tolymphocyte ratio (NLR), and mean platelet volume (MPV) might relate to the evaluation of IS in patients with NVAF.

RDW is a quantitative measurement of differences in the size and volume of circulating red blood cells, and increased RDW reflects the existence of erythrocytopenia, caused by impaired erythropoiesis or erythrocyte degradation, which reflect underlying chronic inflammation and high levels of oxidative stress state (125). In a cross-sectional study, RDW was independent correlated with the increase of $\mathrm{CHADS}_{2}$ and $\mathrm{CHA}_{2} \mathrm{DS}_{2}$-VASc score in patients with NVAF, suggesting that RDW could predict the risk of TE (126). Likewise, a high RDW $(>13.16 \%)$ was shown to be associated with LA thrombosis in patients with NVAF in another study (127). In an up-to 5.2year follow-up "real-world" retrospective cohort study, increased RDW value was independently associated with TE events in patients with NVAF (128). The result of a national study showed that the cumulative stroke incidence in AF patients not taking anticoagulants at baseline increased across RDW quartiles, and after adjusting for known conventional clinical risk factors, RDW was independently associated with stroke (129).

NLR is a marker of systemic inflammation. Specifically, the high neutrophil count reflects subclinical inflammation, while the decrease of lymphocyte count reflects an impairment of the 
adaptive immune system and poor general health status (130). A preliminary study showed that NLR levels were significantly correlated with $\mathrm{CHA}_{2} \mathrm{DS}_{2}$-VASc score in NVAF patients (131). A small sample study showed that the level of NLR in patients with NVAF complicated with IS was higher than that of non-stroke patients (132). A subsequent large sample cohort study further revealed that the incidence rate of stroke increased across NLR quartiles in patients with AF, and NLR refined the risk of stroke across all $\mathrm{CHA}_{2} \mathrm{DS}_{2}$-VASc score strata (133).

MPV is considered to indicate the intensity of the inflammatory process and risk of thrombotic complications (134). Emerging evidence also supports the use of MPV as a biomarker for predicting IS risk in patients with AF. An earlier study showed that MPV was a predictive marker for stroke in patients with AF; its predictive power for stroke was independent of age, gender, and other $\mathrm{CHADS}_{2}$ score components (135). In a study composed of 352 NVAF patients, high MPV was found to be an independent predictor of the composite of IS event and incidental LA thrombus (136). Gul et al. (137) found that MPV levels were significantly higher in acute IS patients with NVAF than those without NVAF. A study of NVAF patients who did not receive anticoagulant therapy showed that MPV was an independent predictor of IS in this population, and the combination of MPV and $\mathrm{CHA}_{2} \mathrm{DS}_{2}$-VASc score had improved predictive value and sensitivity, suggesting MPV could be used as a powerful tool for risk stratification of IS in patients with NVAF (138).

\section{Coagulation Markers}

As a component of Virchow's triad, hypercoagulability is considered an integral mechanism in the pathogenesis of thrombosis (139). Therefore, indicators of coagulation tests might have potential value in predicting AF-related IS. Studies have shown that D-dimer, von Willebrand factor (vWF), and fibrinogen may become new therapeutic targets or auxiliary diagnostic means to assist the risk stratification in AF-related IS.

D-dimer is a specific degradation product of cross-linked fibrin, and a biomarker indicating the activation of coagulation and fibrinolysis (140). In a cross-sectional study, D-dimer levels were positively associated with LA enlargement in anticoagulation-naive patients with an acute IS and NVAF, suggesting that D-dimer could be helpful as a potential surrogate and predictive marker for adverse cardiovascular events in NVAF patients (141). Sub-analysis of several large RCTs testing the efficacy of direct oral anticoagulants vs. warfarin showed that greater levels of D-dimer were associated with higher frequencies of IS or systemic TE events (112, 142, 143). In a study of 509 NVAF patients, D-dimer level in combination with clinical risk factors could effectively predict subsequent TE events even when treated with warfarin (144). In a prospective observational study, AF patients with high levels of D-dimer have increased an risk of composite cardiovascular endpoint (myocardial infarction, stroke or TIA, and arterial embolic events) (145). In a retrospective study, the correlational analysis revealed that $\mathrm{D}$-dimer levels are directly related to stroke volume, severity, and prognosis in patients with NVAF (146). However, a study of 323 NVAF patients, who did not receive anticoagulant therapy, revealed that only the D-dimer level at stroke onset were independent risk factors for IS, while baseline D-dimer levels was not an independent risk factor for IS (147). Therefore, the dynamic detection of $\mathrm{D}$-dimer levels might be necessary for patients with NVAF.

vWF is a plasma glycoprotein synthesized by endothelial cells during endothelial cell activation or injury, which promotes platelet adhesion and aggregation at the site of vascular injury, and is a definite marker of endothelial injury or dysfunction (148). Elevated vWF levels were found in patients with AF compared with healthy controls in an early study (149). A later cross-sectional study showed that raised plasma vWF was associated with four recognized risk factors for IS in AF patients (advancing age, prior IS, HF, and diabetes) (150). In a prospective study, plasma vWf levels were a significant predictor of stroke in NVAF patients taking aspirin, however, after adjustment for other clinical predictors, the relationship between vWf and stroke became non-significant (151). In a 3-year follow-up study, Pinto et al. (152) pointed that baseline vWF was a predictor of newonset IS in patients with chronic NVAF. In another study over a median follow-up of 5.4 years, elevated plasma vWF was an independent risk factor for IS and all-cause death in patients with NVAF (153).

It has been already observed that the levels of fibrinogen were significantly higher in AF patients than in sinus rhythm patients (154). In patients with $\mathrm{AF}$, those with a higher $\mathrm{CHA}_{2} \mathrm{DS}_{2}$-VASc score had increased fibrinogen level compared with those with a low risk of IS (155). Plasma fibrinogen level was associated with a history of stroke in NVAF patients in a case-control study (156). In addition, fibrinogen was also independently and positively associated with leukoaraiosis and periventricular hyperintensity in patients with stroke and AF (157).

\section{Lipid Markers}

Dyslipidemia is closely associated with cardiovascular disease and is the important predictor and therapeutic target of cardiovascular risk. After optimizing the stratification of risk factors other than $\mathrm{CHA}_{2} \mathrm{DS}_{2}$-VASc scores, a recently published meta-analysis showed that the levels of low-density lipoprotein cholesterol (LDL-C) and total cholesterol in the IS group were higher than those in the non-stroke group in NVAF patients (28). A case-control study showed that LDL-C is an independent predictor of IS in patients with NVAF and could improve stroke risk stratification (158). However, another large sample retrospective cohort study did not reach a consistent conclusion. The study carried by Omelchenko et al. (159) showed that LDLC levels were not associated with the risk of IS in NVAF patients treated with oral anticoagulants, and they interpreted this lack of association as the high selectivity of patients (patient taking oral anticoagulants) and the high proportion of TE etiology for IS in AF patients. On the other hand, compliance with statins was associated with a reduced risk of recurrent IS in patients with AF, suggesting that AF status should not be a condition for excluding statins as a condition for secondary stroke prevention in patients with IS (160). High-density lipoprotein cholesterol (HDL-C) is an anti-atherosclerotic lipoprotein and is reported negatively correlated with the risk of IS (161). Our previous 
case-control study has shown that the LDL-C/HDL-C ratio is a predictor of IS in patients with NVAF (162). Elevated LDL-C/HDL-C ratio may suggest that the imbalance between atherosclerotic and anti-atherosclerotic components, and the increase of pro-inflammatory components, which might both affect the occurrence and development of IS. In a small-sample study, NVAF patients with IS have higher levels of lipoprotein (a) $[\mathrm{Lp}(\mathrm{a})]$, and $\mathrm{Lp}(\mathrm{a}) \geq 30 \mathrm{mg} / \mathrm{dL}$ is associated with TE events in patients with NVAF (163). However, results from ARIC cohort showed that high $\operatorname{Lp}(\mathrm{a})$ levels were associated with increased IS risk, primarily among individuals without AF but not in those with AF (164). Overall, at present, the results of the relevant observational studies on blood lipids and IS in patients with NVAF are contradictory. High-quality evidence is lacking. Further studies are still needed to confirm the relationship between blood lipids and IS in patients with NVAF.

\section{Oxidative Stress and Inflammation Biomarker}

Oxidative stress and inflammation are tightly linked to AF (165). Therefore, markers of inflammation might be identified as predictors of AF-related IS. Numbers studies have shown that various inflammation markers, such as C-reactive protein (CRP), hyperuricemia, soluble CD40 ligand (sCD40L), homocysteine (Hcy), adiponectin (APN), growth differentiation factor 15 (GDF-15), circulating interleukins (IL) might be useful biomarkers for predicting AF-related IS.

CRP is the most commonly used measure of the inflammatory response. A high CRP level was associated with LA enlargement and depression of contractile function of LA in paroxysmal AF patients (166). Secondary analysis of SPAF III clinical trial (167) and RE-LY trial (168) showed that CRP was positively correlated to stroke risk in AF patients taking aspirin or oral anticoagulant.

Hyperuricemia is a known independent competing risk factor for AF (169). Recent studies also demonstrated that hyperuricemia was associated with IS among AF patients. Several case-control studies showed that uric acid level was closely associated with LA stasis (composed of LA thrombus, LASEC) in patients with NVAF (170-173). In a study of NVAF patients at clinically low-intermediate risk $\left(\mathrm{CHA}_{2} \mathrm{DS}_{2}\right.$-VASc score $=0$ or 1 ), uric acid levels were higher in those with transesophageal echocardiography (TEE) thromboembolic risk than in those without TEE risk (174). Hyperuricemia was shown to dependently predict IS after adjusting for $\mathrm{CHA}_{2} \mathrm{DS}_{2}$-VASc score and other comorbidities in a cohort study, and could further stratify low-risk patients into 2 groups with different stroke rates (175).

sCD40L has been considered as a marker of thrombosis and inflammation in several diseases. In patients with AF, the presence of LA thrombus was associated with significantly increased levels of sCD40L (176). In a study of 44 consecutive outpatients with chronic NVAF, plasma sCD40L was the independent variable for LASEC or LA thrombus formation, and for cerebrovascular events (177). Another larger study came to a similar conclusion, which enhanced soluble CD40L level was a predictor of fatal and non-fatal IS in patients with NVAF (178).
In an early study, hyperhomocysteinemia is associated with the presence of LA thrombus in stroke patients with NVAF (179). A later study showed that increased fasting Hcy levels were independently associated with a history of IS in NVAF patients hospitalized for cardiac reasons (180). AF and elderly patients were shown to have elevated Hcy levels, which might result in the correlation between high levels of Hcy and stroke in the elderly AF patients (181).

APN possesses anti-inflammatory and antiatherogenic effects. In a cross-sectional study, APN levels were higher in anticoagulated AF patients with LASEC, a LA thrombus, or a LAA thrombus (182). Additionally, AF patients at high risk of stroke disclosed low levels of APN (183). However, in a study of 918 stable anticoagulated outpatients with NVAF, APN was neither predictive of stroke/TE in both male and female patients (184).

GDF-15 is a peptide hormone and a divergent member of the transforming growth factor-beta superfamily (185). In a cross-sectional study, elevated GDF-15 was associated with the presence of LA/LAA thrombus in NVAF patients without anticoagulation (186). Insights from ARISTOTLE trial (187) and ENGAGE AF-TIMI 48 (122) also showed that GDF-15 was a risk factor for stroke in AF patients with anticoagulation therapy.

At present, researchers are also focusing on the correlation between other markers of inflammation and AF-related IS. In a recent pilot study, trimethylamine $\mathrm{N}$-oxide (TMAO) was an independent predictor in IS in AF patients, and the level of TMAO was correlated with the $\mathrm{CHA}_{2} \mathrm{DS}_{2}$-VASc score (188). Results of a two-sample Mendelian randomization study showed a positive association of IL-1ra with cardioembolic stroke and inverse associations of IL-6 with cardioembolic stroke (189). In a 3-year follow-up study, baseline plasma levels of TNF- $\alpha$ and IL- 6 are predictors of new-onset IS at follow-up in patients with chronic NVAF (152). In addition, evidence from a metaanalysis showed that increased circulating plasminogen activator inhibitor-1 and thrombin-antithrombin levels were significantly associated with subsequent stroke in patients with AF (190).

In general, many studies have shown that indicators of inflammatory could predict stroke in NVAF patients. However, these biomarkers are diverse and lack specificity. Therefore, more research is needed to find reliable inflammatory markers.

\section{Fibrosis Markers}

Cardiac (especially atrial) fibrosis is a critical feature of myocardial remodeling. The imaging manifestations of cardiac fibrosis, such as increased LAD, LA strain, and LGE, have been confirmed to be associated with an increased risk of IS in patients with AF as described previously. Several studies have also shown that circulating fibrosis biomarkers are associated with AF-related IS. High Gal-3 level was closely related to LAA flow velocity and occurrence of LAA thrombus in patients with NVAF (191). However, peripheral levels of circulating fibrosis biomarkers are susceptible to non-cardiac fibrosis, and might not be representative of the severity of cardiac fibrosis (192). Therefore, more research is required to explore the usefulness of circulating fibrosis in predicting AF-related IS in the future. 
TABLE 2 | Major verified biomarkers adding in stroke/TE risk stratification beyond $\mathrm{CHA}_{2} \mathrm{DS}_{2}$-VASc score in AF patients.

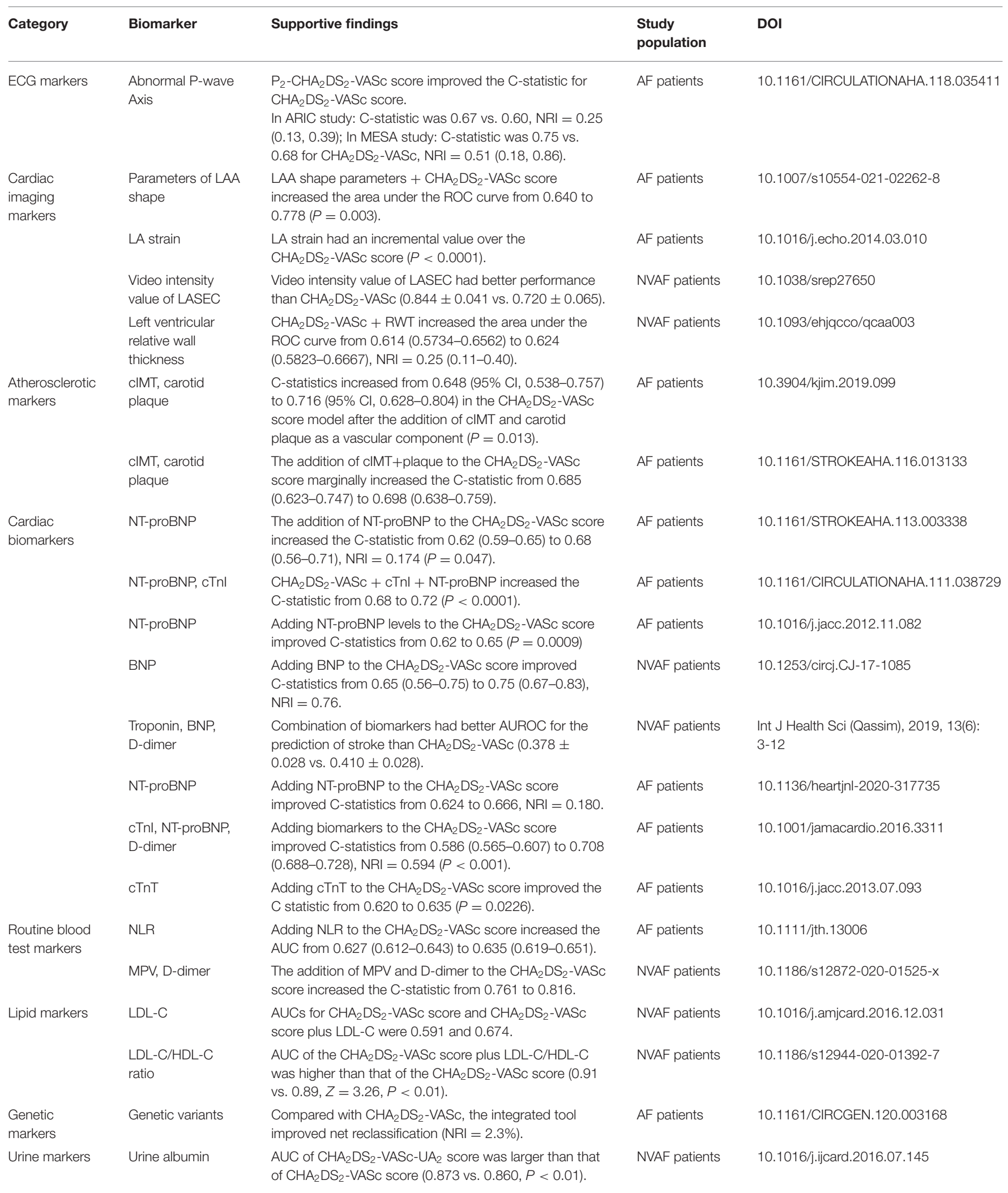

TE, thromboembolism; AF, atrial fibrillation; ECG, electrocardiogram; NRI, net reclassification improvement; LAA, left atrial appendage; LA, left atrium; LASEC, left atrial spontaneous echo contrast; NVAF, non-valvular atrial fibrillation; RWT, relative wall thickness; ROC, receiver operating characteristic curve; cIMT, carotid intima-media thickness; NT-proBNP, N-terminal prohormone of brain natriuretic peptide; CTnl, cardiac troponin I; BNP, B-type natriuretic peptide; AUROC, area under the receiver operating characteristic curve; CTnT, cardiac troponin T; NLR, neutrophil-to-lymphocyte ratio; MPV, mean platelet volume. 


\section{NOVEL MARKERS OF GENETICS AND BIOINFORMATICS}

At present, the research field of genetics and bioinformatics, and their applications to AF continue to evolve rapidly (193). Existing studies have identified a variety of genetic markers of AF-related IS through single nucleotide polymorphisms (SNP) analysis, genome-wide association study (GWAS), bioinformatic analysis, and omics. In an early study, a genetic risk score of twelve SNPs could identify individuals at increased risk for future AF and stroke (194). Based on the discovery of GWAS, copy number variation and SNPs could be genetic predictors of risk of TE and cardioembolic stroke for patients with AF (195-197). In a recent update study using data from the largest available GWAS in Europeans, a polygenic risk score incorporated of over half a million genetic variants could significantly improve net reclassification compared with $\mathrm{CHA}_{2} \mathrm{DS}_{2}$-VASc score in predicting IS in patients with AF (198). Two studies analyzed datasets of Gene Expression Omnibus via bioinformatic analysis, respectively, and identified several genes which were involved in AF-related stroke $(199,200)$. In addition, studies have shown that abnormal expression of non-coding RNAs, such as lncRNA ANRIL, hsa-miR-22-3p, was associated with functional outcome or prognosis in AF patients, and could potentially serve as potential biomarkers for AF-related IS $(201,202)$. On the basis of current research, it can be expected that new and promising genetics biomarkers for AF-related IS will be further discovered in the near future.

\section{SUMMARY AND PERSPECTIVE}

Biomarkers have become an important integral to the clinical practice of AF. The purpose of this review is to acquaint clinicians and researchers with the progress of biomarkers in AF-related IS. In summary, although a great deal of research has been done on biomarkers for IS prediction in NVAF patients as mentioned above, most potential biomarkers have not yet been translated into clinical use. Nevertheless, these biomarkers can help us to better understand the etiology and pathophysiology of AFrelated IS.

An ideal biomarker should be simple, practical, inexpensive, and with high sensitivity. Based on current evidence, we acknowledge that non-paroxysmal AF type, carotid plaque, cardiac troponin, NT-proBNP, and D-dimer are promising biomarkers for IS in NVAF patients since these biomarkers strike a balance between practicality and simplicity. They are easily acquired in clinical practice. Meanwhile, these markers are cardiac-specific or reflecting AF features and pathophysiological processes of stroke. Moreover, the clinical value of these markers has been confirmed by multiple studies.

It is important to recognize, however, that the existing studies have significant limitations. First, most studies are observational studies with small samples size, which limits the clinical value of the identified markers. At the same time, limited by the study design, most studies investigate the correlation between only one biomarker and IS in AF patients, and a single biomarker might be disturbed by other confounding factors, and only a few studies evaluate the role of multiple biomarkers (203). Second, the majority of the study population was treated patients with anticoagulation therapy, and studies focusing on un-anticoagulated patients and other populations are lacking. Third, the end-points of the studies are not uniform, such as IS, systemic TE, TIA, and the combination of them. Additionally, the inclusion criteria and covariates are inconsistent between the studies. Forth, there may be a time-dependent correlation between some biomarkers and IS outcome, and the assessment of a baseline level of the biomarker may not draw a reliable conclusion. For different research investigating the same biomarker, the cut-off values of the biomarker are often incongruent, which makes it impossible to combine the results of the studies. Fifth, the majority of studies merely find the differentially expressed biomarker in AF patients with stroke compared with those without stroke. Almost all the studies fail to show a valuable improvement in clinical usefulness, although a slightly improved predictive performance for IS compared with the commonly used risk score is shown in some studies (Table 2) $(204,205)$.

Incorporating biomarkers into existing models may allow improved predictive accuracy and guide individualized anticoagulation treatment, but it brings complexity. Given these uncertainties, what should the clinician do? First, we believe it is still necessary to discover novel biomarkers and verify the predictive value of current markers in large-scale prospective cohort studies. Studies in patients with $\mathrm{CHA}_{2} \mathrm{DS}_{2}$ VASc score of $0-1$ are encouraged, thereby improving the prognosis of patients who are not provided with a clear indication for oral anticoagulants in current guidelines. In addition, it is important to find biomarkers that could distinguish between ischemic and hemorrhagic stroke, because most existing indicators in $\mathrm{CHA}_{2} \mathrm{DS}_{2}$-VASc score indicate both bleeding and ischemia. Second, in view of the complexity and interdependence of pathophysiological pathways for AF-related IS, multi-omics and high-throughput analysis should be used to find multiple biomarkers to discover new therapeutic targets. Third, comprehensive studies are needed to integrate current biomarkers and clinical score to optimize the prevention of IS in patients with NVAF. At last, the effectiveness of the "biomarker plus $\mathrm{CHA}_{2} \mathrm{DS}_{2}$-VASc" score-guided treatment strategy in NVAF patients should also be evaluated.

\section{AUTHOR CONTRIBUTIONS}

LXS, LZ, YKG, HXS, XXZ, and YKB searched literatures and prepared the manuscript. XHZ and BPT provided funds support, conceived the idea, reviewed the drafts, and provided important information for the completion of this manuscript. All authors contributed to the writing and final approval of the manuscript.

\section{FUNDING}

This work was supported by the Natural Science Foundation of China (Grant numbers: 81873488 and 
82060069), National Key R\&D Program of China (Grant number: 2016YFC0900905), and Xinjiang Key Laboratory of Cardiac Electrophysiology and Remodeling. The

\section{REFERENCES}

1. Rahman F, Kwan GF, Benjamin EJ. Global epidemiology of atrial fibrillation. Nat Rev Cardiol. (2014) 11:639-54. doi: 10.1038/nrcardio.2014.118

2. Mou L, Norby FL, Chen LY, O’Neal WT, Lewis TT, Loehr LR, et al. Lifetime risk of atrial fibrillation by race and socioeconomic status: ARIC study (Atherosclerosis Risk in Communities). Circ Arrhythm Electrophysiol. (2018) 11:e006350. doi: 10.1161/CIRCEP.118.006350

3. Weng LC, Preis SR, Hulme OL, Larson MG, Choi SH, Wang B, et al. Genetic predisposition, clinical risk factor burden, and lifetime risk of atrial Fibrillation. Circulation. (2018) 137:1027-38. doi: 10.1161/CIRCULATIONAHA.117.031431

4. Staerk L, Sherer JA, Ko D, Benjamin EJ, Helm RH. Atrial fibrillation: epidemiology, pathophysiology, clinical outcomes. Circ Res. (2017) 120:1501-17. doi: 10.1161/CIRCRESAHA.117.309732

5. Mozaffarian D, Benjamin EJ, Go AS, Arnett DK, Blaha MJ, Cushman $\mathrm{M}$, et al. Heart disease and stroke statistics-2016 update: a report from the american heart association. Circulation. (2016) 133:e38-360. doi: 10.1161/CIR.0000000000000350

6. Pistoia F, Sacco S, Tiseo C, Degan D, Ornello R, Carolei A. The epidemiology of atrial fibrillation and stroke. Cardiol Clin. (2016) 34:255-68. doi: 10.1016/j.ccl.2015.12.002

7. López-López JA, Sterne JAC, Thom HHZ, Higgins JPT, Hingorani AD, Okoli $\mathrm{GN}$, et al. Oral anticoagulants for prevention of stroke in atrial fibrillation: systematic review, network meta-analysis, and cost effectiveness analysis. BMJ. (2017) 359:j5058. doi: 10.1136/bmj.j5058

8. Chiang CE, Okumura K, Zhang S, Chao TF, Siu CW, Wei Lim T, et al. 2017 consensus of the Asia Pacific Heart Rhythm Society on stroke prevention in atrial fibrillation. J Arrhythm. (2017) 33:345-67. doi: 10.1016/j.joa.2017.05.004

9. January CT, Wann LS, Calkins H, Chen LY, Cigarroa JE, Cleveland C Jr, et al. 2019 AHA/ACC/HRS focused update of the 2014 AHA/ACC/HRS guideline for the management of patients with atrial fibrillation: a report of the american college of cardiology/american heart association task force on clinical practice guidelines and the heart rhythm society. J Am Coll Cardiol. (2019) 74:104-32. doi: 10.1016/j.jacc.2019.01.011

10. Hindricks G, Potpara T, Dagres N, Arbelo E, Bax JJ, Blomström-Lundqvist C, et al. 2020 ESC Guidelines for the diagnosis and management of atrial fibrillation developed in collaboration with the European Association of Cardio-Thoracic Surgery (EACTS). Eur Heart J. (2021) 42:373-498. doi: 10.1093/eurheartj/ehaa612

11. Nielsen PB, Larsen TB, Skjøth F, Overvad TF, Lip GY. Stroke and thromboembolic event rates in atrial fibrillation according to different guideline treatment thresholds: a nationwide cohort study. Sci Rep. (2016) 6:27410. doi: 10.1038/srep27410

12. Borre ED, Goode A, Raitz G, Shah B, Lowenstern A, Chatterjee R, et al. Predicting thromboembolic and bleeding event risk in patients with nonvalvular atrial fibrillation: a systematic review. Thromb Haemost. (2018) 118:2171-87. doi: 10.1055/s-0038-1675400

13. Lyngbakken MN, Myhre PL, Røsj,ø H, Omland T. Novel biomarkers of cardiovascular disease: applications in clinical practice. Crit Rev Clin Lab Sci. (2019) 56:33-60. doi: 10.1080/10408363.2018.1525335

14. Wettersten N, Horiuchi Y, Maisel A. Advancements in biomarkers for cardiovascular disease: diagnosis, prognosis, and therapy. Fac Rev. (2021) 10:34. doi: 10.12703/r/10-34

15. Biomarkers Definitions Working Group. Biomarkers and surrogate endpoints: preferred definitions and conceptual framework. Clin Pharmacol Ther. (2001) 69:89-95. doi: 10.1067/mcp.2001.113989

16. Hijazi Z, Oldgren J, Siegbahn A, Granger CB, Wallentin L. Biomarkers in atrial fibrillation: a clinical review. Eur Heart J. (2013) 34:1475-80. doi: 10.1093/eurheartj/eht024

17. Szymanski FM, Lip GY, Filipiak KJ, Platek AE, Hrynkiewicz-Szymanska A, Opolski G. Stroke risk factors beyond the $\mathrm{CHA}_{2} \mathrm{DS}_{2}$-VASc funders had no role in the study design, data collection and analysis, decision to publish, or preparation of the manuscript. score: can we improve our identification of "High Stroke Risk" patients with atrial fibrillation? Am J Cardiol. (2015) 116:1781-8. doi: 10.1016/j.amjcard.2015.08.049

18. Alkhouli M, Friedman PA. Ischemic stroke risk in patients with nonvalvular atrial fibrillation: jacc review topic of the week. J Am Coll Cardiol. (2019) 74:3050-65. doi: 10.1016/j.jacc.2019.10.040

19. Ioannou A, Papageorgiou N, Falconer D, Rehal O, Sewart E, Zacharia E, et al. Biomarkers associated with stroke risk in atrial fibrillation. Curr Med Chem. (2019) 26:803-23. doi: 10.2174/0929867324666170718120651

20. Jagadish PS, Kabra R. Stroke risk in atrial fibrillation: beyond the CHA(2)DS(2)-VASc score. Curr Cardiol Rep. (2019) 21:95. doi: 10.1007/s11886-019-1189-6

21. Pallazola VA, Kapoor RK, Kapoor K, McEvoy JW, Blumenthal RS, Gluckman TJ. Anticoagulation risk assessment for patients with non-valvular atrial fibrillation and venous thromboembolism: a clinical review. Vasc Med. (2019) 24:141-52. doi: 10.1177/1358863X18819816

22. Gage BF, Waterman AD, Shannon W, Boechler M, Rich MW, Radford MJ. Validation of clinical classification schemes for predicting stroke: results from the National Registry of Atrial Fibrillation. JAMA. (2001) 285:2864-70. doi: 10.1001/jama.285.22.2864

23. Olesen JB, Torp-Pedersen C, Hansen ML, Lip GY. The value of the CHA2DS2-VASc score for refining stroke risk stratification in patients with atrial fibrillation with a CHADS2 score 0-1: a nationwide cohort study. Thromb Haemost. (2012) 107:1172-9. doi: 10.1160/TH12-03-0175

24. Olesen JB, Torp-Pedersen C. Stroke risk in atrial fibrillation: do we anticoagulate CHADS2 or CHA2DS2-VASc $\geq 1$, or higher? Thromb Haemost. (2015) 113:1165-9. doi: 10.1160/TH15-02-0154

25. Lip GY, Nieuwlaat R, Pisters R, Lane DA, Crijns HJ. Refining clinical risk stratification for predicting stroke and thromboembolism in atrial fibrillation using a novel risk factor-based approach: the euro heart survey on atrial fibrillation. Chest. (2010) 137:263-72. doi: 10.1378/chest.09-1584

26. Chen JY, Zhang AD, Lu HY, Guo J, Wang FF, Li ZC. CHADS2 versus CHA2DS2-VASc score in assessing the stroke and thromboembolism risk stratification in patients with atrial fibrillation: a systematic review and meta-analysis. J Geriatr Cardiol. (2013) 10:258-66. doi: 10.3969/j.issn.1671-5411.2013.03.004

27. Huang D, Anguo L, Yue WS, Yin L, Tse HF, Siu CW. Refinement of ischemic stroke risk in patients with atrial fibrillation and CHA2 DS2 -VASc score of 1. Pacing Clin Electrophysiol. (2014) 37:1442-7. doi: 10.1111/pace. 12445

28. Li W, Zeng X, Xu L, Wang T, Lin W, Li Y, et al. Optimized stratification of risk factors in and beyond the CHA 2 DS 2 -VASc score to differentiate the real thromboembolic risk in mainland China: a systematic review and metaanalysis. Ann Palliative Med. (2020) 9:4252-61. doi: 10.21037/apm-20-297

29. Golwala H, Jackson, 2nd LR, Simon DN, Piccini JP, Gersh B, Go AS, et al. Racial/ethnic differences in atrial fibrillation symptoms, treatment patterns, and outcomes: insights from outcomes registry for better informed treatment for atrial fibrillation registry. Am Heart J. (2016) 174:29-36. doi: 10.1016/j.ahj.2015.10.028

30. Kim TH, Yang PS, Yu HT, Jang E, Uhm JS, Kim JY, et al. Age threshold for ischemic stroke risk in atrial fibrillation. Stroke. (2018) 49:1872-9. doi: 10.1161/STROKEAHA.118.021047

31. Kodani E, Akao M. Atrial fibrillation and stroke prevention: state of the art-epidemiology and pathophysiology: new risk factors, concepts and controversies. Europ Heart J Suppl. (2020) 22:01-3. doi: 10.1093/eurheartj/suaal76

32. Maheshwari A, Norby FL, Roetker NS, Soliman EZ, Koene RJ, Rooney $\mathrm{MR}$, et al. Refining prediction of atrial fibrillation-related stroke using the P(2)-CHA(2)DS(2)-VASc score. Circulation. (2019) 139:180-91. doi: 10.1161/CIRCULATIONAHA.118.035411

33. He H, Guo J, Zhang A. The value of urine albumin in predicting thromboembolic events for patients with non-valvular atrial fibrillation. Int J Cardiol. (2016) 221:827-30. doi: 10.1016/j.ijcard.2016.07.145 
34. Kabra R, Girotra S, Vaughan Sarrazin M. Refining stroke prediction in atrial fibrillation patients by addition of african-american ethnicity to CHA2DS2-VASc score. J Am Coll Cardiol. (2016) 68:461-70. doi: 10.1016/j.jacc.2016.05.044

35. Cha MJ, Cho Y, Oh IY, Choi EK, Oh S. Validation of conventional thromboembolic risk factors in a Korean atrial fibrillation populationsuggestion for a novel scoring system, CHA(2)DS(2)-VAK. Circ J. (2018) 82:2970-5. doi: 10.1253/circj.CJ-18-0218

36. Chao TF, Lip GY, Liu CJ, Tuan TC, Chen SJ, Wang KL, et al. Validation of a modified CHA2DS2-VASc score for stroke risk stratification in Asian patients with atrial fibrillation: a nationwide cohort study. Stroke. (2016) 47:2462-9. doi: 10.1161/STROKEAHA.116.013880

37. Singer DE, Chang Y, Borowsky LH, Fang MC, Pomernacki NK, Udaltsova $\mathrm{N}$, et al. A new risk scheme to predict ischemic stroke and other thromboembolism in atrial fibrillation: the ATRIA study stroke risk score. J Am Heart Assoc. (2013) 2:e000250. doi: 10.1161/JAHA.113.000250

38. Fox KAA, Lucas JE, Pieper KS, Bassand JP, Camm AJ, Fitzmaurice DA, et al. Improved risk stratification of patients with atrial fibrillation: an integrated GARFIELD-AF tool for the prediction of mortality, stroke and bleed in patients with and without anticoagulation. BMJ Open. (2017) 7:e017157. doi: 10.1136/bmjopen-2017-017157

39. Hijazi Z, Lindbäck J, Alexander JH, Hanna M, Held C, Hylek EM, et al. The ABC (age, biomarkers, clinical history) stroke risk score: a biomarkerbased risk score for predicting stroke in atrial fibrillation. Eur Heart J. (2016) 37:1582-90. doi: 10.1093/eurheartj/ehw054

40. Al-Khatib SM, Thomas L, Wallentin L, Lopes RD, Gersh B, Garcia D, et al. Outcomes of apixaban vs. warfarin by type and duration of atrial fibrillation: results from the ARISTOTLE trial. Eur Heart J. (2013) 34:246471. doi: 10.1093/eurheartj/eht135

41. Steinberg BA, Hellkamp AS, Lokhnygina Y, Patel MR, Breithardt G, Hankey GJ, et al. Higher risk of death and stroke in patients with persistent vs. paroxysmal atrial fibrillation: results from the ROCKET-AF Trial. Eur Heart J. (2015) 36:288-96. doi: 10.1093/eurheartj/ehu359

42. Vanassche T, Lauw MN, Eikelboom JW, Healey JS, Hart RG, Alings M, et al. Risk of ischaemic stroke according to pattern of atrial fibrillation: analysis of 6563 aspirin-treated patients in ACTIVE-A and AVERROES. Eur Heart J. (2015) 36:281-7a. doi: 10.1093/eurheartj/ehu307

43. Link MS, Giugliano RP, Ruff CT, Scirica BM, Huikuri H, Oto A, et al. Stroke and mortality risk in patients with various patterns of atrial fibrillation: results from the ENGAGE AF-TIMI 48 trial (Effective Anticoagulation With Factor Xa Next Generation in Atrial Fibrillation-Thrombolysis in Myocardial Infarction 48). Circ Arrhythm Electrophysiol. (2017) 10:e004267. doi: 10.1161/CIRCEP.116.004267

44. Takabayashi K, Hamatani Y, Yamashita Y, Takagi D, Unoki T, Ishii M, et al. Incidence of stroke or systemic embolism in paroxysmal versus sustained atrial fibrillation: the fushimi atrial fibrillation registry. Stroke. (2015) 46:3354-61. doi: 10.1161/STROKEAHA.115.010947

45. Ganesan AN, Chew DP, Hartshorne T, Selvanayagam JB, Aylward PE, Sanders $\mathrm{P}$, et al. The impact of atrial fibrillation type on the risk of thromboembolism, mortality, and bleeding: a systematic review and metaanalysis. Eur Heart J. (2016) 37:1591-602. doi: 10.1093/eurheartj/ehw007

46. Kirchhof P, Benussi S, Kotecha D, Ahlsson A, Atar D, Casadei B, et al. 2016 ESC Guidelines for the management of atrial fibrillation developed in collaboration with EACTS. Eur Heart J. (2016) 37:2893-962. doi: 10.1093/eurheartj/ehw210

47. Diederichsen SZ, Haugan KJ, Brandes A, Lanng MB, Graff C, Krieger $D$, et al. Natural history of subclinical atrial fibrillation detected by implanted loop recorders. J Am Coll Cardiol. (2019) 74:2771-81. doi: 10.1016/j.jacc.2019.09.050

48. Pastori D, Miyazawa K, Li Y, Székely O, Shahid F, Farcomeni A, et al. Atrial high-rate episodes and risk of major adverse cardiovascular events in patients with cardiac implantable electronic devices. Clin Res Cardiol. (2020) 109:96-102. doi: 10.1007/s00392-019-01493-Z

49. Glotzer TV, Hellkamp AS, Zimmerman J, Sweeney MO, Yee R, Marinchak $\mathrm{R}$, et al. Atrial high rate episodes detected by pacemaker diagnostics predict death and stroke: report of the atrial diagnostics ancillary study of the MOde Selection Trial (MOST). Circulation. (2003) 107:1614-9. doi: 10.1161/01.CIR.0000057981.70380.45
50. Healey JS, Connolly SJ, Gold MR, Israel CW, Van Gelder IC, Capucci A, et al. Subclinical atrial fibrillation and the risk of stroke. N Engl J Med. (2012) 366:120-9. doi: 10.1056/NEJMoa1105575

51. Boriani G, Laroche C, Diemberger I, Fantecchi E, Popescu MI, Rasmussen LH, et al. Asymptomatic atrial fibrillation: clinical correlates, management, and outcomes in the EORP-AF Pilot General Registry. Am J Med. (2015) 128:509-18.e502. doi: 10.1016/j.amjmed.2014.11.026

52. Potpara TS, Polovina MM, Marinkovic JM, Lip GY. A comparison of clinical characteristics and long-term prognosis in asymptomatic and symptomatic patients with first-diagnosed atrial fibrillation: the Belgrade Atrial Fibrillation Study. Int J Cardiol. (2013) 168:4744-9. doi: 10.1016/j.ijcard.2013.07.234

53. Boriani G, Glotzer TV, Santini M, West TM, De Melis M, Sepsi M, et al. Device-detected atrial fibrillation and risk for stroke: an analysis of $>10,000$ patients from the SOS AF project (Stroke preventiOn Strategies based on Atrial Fibrillation information from implanted devices). Eur Heart J. (2014) 35:508-16. doi: 10.1093/eurheartj/eht491

54. Han L, Askari M, Altman RB, Schmitt SK, Fan J, Bentley JP, et al. Atrial fibrillation burden signature and near-term prediction of stroke: a machine learning analysis. Circ Cardiovasc Qual Outcomes. (2019) 12:e005595. doi: 10.1161/CIRCOUTCOMES.118.005595

55. Al-Gibbawi M, Ayinde HO, Bhatia NK, El-Chami MF, Westerman SB, Leon $\mathrm{AR}$, et al. Relationship between device-detected burden and duration of atrial fibrillation and risk of ischemic stroke. Heart Rhythm. (2021) 18:338-346. doi: 10.1016/j.hrthm.2020.10.017

56. Benezet-Mazuecos J, Rubio JM, Cortés M, Iglesias JA, Calle S, de la Vieja JJ, et al. Silent ischaemic brain lesions related to atrial high rate episodes in patients with cardiac implantable electronic devices. Europace. (2015) 17:364-9. doi: 10.1093/europace/euu267

57. Icen YK, Koc AS. Silent ischemic brain lesions detected by multi-slice computed tomography are associated with subclinical atrial fibrillation in patients with cardiac resynchronization therapy. Postepy Kardiol Interwencyjnej. (2018) 14:285-90. doi: 10.5114/aic.2018.78332

58. Daoud EG, Glotzer TV, Wyse DG, Ezekowitz MD, Hilker C, Koehler J, et al. Temporal relationship of atrial tachyarrhythmias, cerebrovascular events, and systemic emboli based on stored device data: a subgroup analysis of TRENDS. Heart Rhythm. (2011) 8:1416-23. doi: 10.1016/j.hrthm.2011.04.022

59. Boriani G, Vitolo M, Diemberger I, Proietti M, Valenti AC, Malavasi VL, et al. Optimizing indices of AF susceptibility and burden to evaluate AF severity, risk and outcomes. Cardiovasc Res. (2021) 116:1097-100. doi: $10.1093 / \mathrm{cvr} / \mathrm{cvab} 147$

60. Watson T, Shantsila E, Lip GY. Mechanisms of thrombogenesis in atrial fibrillation: Virchow's triad revisited. Lancet. (2009) 373:155-66. doi: 10.1016/S0140-6736(09)60040-4

61. Al-Saady NM, Obel OA, Camm AJ. Left atrial appendage: structure, function, and role in thromboembolism. Heart. (1999) 82:547-54. doi: 10.1136/hrt.82.5.547

62. Di Biase L, Santangeli P, Anselmino M, Mohanty P, Salvetti I, Gili S, et al. Does the left atrial appendage morphology correlate with the risk of stroke in patients with atrial fibrillation? Results from a multicenter study. J Am Coll Cardiol. (2012) 60:531-8. doi: 10.1016/j.jacc.2012.04.032

63. Anan AR, Fareed J, Suhaib J, Rafat R, Murad D, Isam B, et al. Left atrial appendage morphology as a determinant for stroke risk assessment in atrial fibrillation patients: systematic review and meta-analysis. J Atr Fibrillation. (2019) 12:2183. doi: 10.4022/jafib.2183

64. Wu L, Liang E, Fan S, Zheng L, Du Z, Liu S, et al. Relation of left atrial appendage morphology determined by computed tomography to prior stroke or to increased risk of stroke in patients with atrial fibrillation. Am J Cardiol. (2019) 123:1283-6. doi: 10.1016/j.amjcard.2019.01.024

65. He J, Fu Z, Yang L, Liu W, Tian Y, Liu Q, et al. The predictive value of a concise classification of left atrial appendage morphology to thrombosis in non-valvular atrial fibrillation patients. Clin Cardiol. (2020) 43:789-95. doi: $10.1002 /$ clc. 23381

66. Yaghi S, Chang AD, Akiki R, Collins S, Novack T, Hemendinger M, et al. The left atrial appendage morphology is associated with embolic stroke subtypes using a simple classification system: a proof of concept study. J Cardiovasc Comput Tomogr. (2020) 14:27-33. doi: 10.1016/j.jcct.2019.04.005 
67. Bieging ET, Morris A, Chang L, Dagher L, Marrouche NF, Cates J. Statistical shape analysis of the left atrial appendage predicts stroke in atrial fibrillation. Int J Cardiovasc Imaging. (2021). doi: 10.1007/s10554-021-02262-8. [Epub ahead of print].

68. Zhao Y, Zhang PP, Xu QF, Yu LW, Yu Y, Li YG. Relationship between left atrial appendage morphology and thrombus formation in patients with atrial fibrillation. Int J Cardiol. (2015) 188:86-8. doi: 10.1016/j.ijcard.2015.04.033

69. Nedios S, Kornej J, Koutalas E, Bertagnolli L, Kosiuk J, Rolf S, et al. Left atrial appendage morphology and thromboembolic risk after catheter ablation for atrial fibrillation. Heart Rhythm. (2014) 11:2239-46. doi: 10.1016/j.hrthm.2014.08.016

70. Goldman ME, Pearce LA, Hart RG, Zabalgoitia M, Asinger RW, Safford R, et al. Pathophysiologic correlates of thromboembolism in nonvalvular atrial fibrillation: I. Reduced flow velocity in the left atrial appendage (The Stroke Prevention in Atrial Fibrillation [SPAF-III] study). J Am Soc Echocardiogr. (1999) 12:1080-7. doi: 10.1016/S0894-7317(99)70105-7

71. Lee JM, Shim J, Uhm JS, Kim YJ, Lee HJ, Pak HN, et al. Impact of increased orifice size and decreased flow velocity of left atrial appendage on stroke in nonvalvular atrial fibrillation. Am J Cardiol. (2014) 113:963-9. doi: 10.1016/j.amjcard.2013.11.058

72. Delgado V, Di Biase L, Leung M, Romero J, Tops LF, Casadei B, et al. Structure and function of the left atrium and left atrial appendage: AF and stroke implications. J Am Coll Cardiol. (2017) 70:3157-72. doi: $10.1016 /$ j.jacc.2017.10.063

73. Tufano A, Galderisi M. Can echocardiography improve the prediction of thromboembolic risk in atrial fibrillation? Evidences and perspectives. Intern Emerg Med. (2020) 15:935-43. doi: 10.1007/s11739-020-02303-5

74. Hamatani Y, Ogawa H, Takabayashi K, Yamashita Y, Takagi D, Esato M, et al. Left atrial enlargement is an independent predictor of stroke and systemic embolism in patients with non-valvular atrial fibrillation. Sci Rep. (2016) 6:31042. doi: 10.1038/srep31042

75. Benjamin EJ, D’Agostino RB, Belanger AJ, Wolf PA, Levy D. Left atrial size and the risk of stroke and death. The Framingham Heart Study. Circulation. (1995) 92:835-41. doi: 10.1161/01.CIR.92.4.835

76. Paciaroni M, Agnelli G, Falocci N, Caso V, Becattini C, Marcheselli S, et al. Prognostic value of trans-thoracic echocardiography in patients with acute stroke and atrial fibrillation: findings from the RAF study. J Neurol. (2016) 263:231-7. doi: 10.1007/s00415-015-7957-3

77. Daccarett M, Badger TJ, Akoum N, Burgon NS, Mahnkopf C, Vergara $\mathrm{G}$, et al. Association of left atrial fibrosis detected by delayedenhancement magnetic resonance imaging and the risk of stroke in patients with atrial fibrillation. J Am Coll Cardiol. (2011) 57:831-8. doi: 10.1016/j.jacc.2010.09.049

78. King JB, Azadani PN, Suksaranjit P, Bress AP, Witt DM, Han FT, et al. Left atrial fibrosis and risk of cerebrovascular and cardiovascular events in patients with atrial fibrillation. J Am Coll Cardiol. (2017) 70:1311-21. doi: $10.1016 /$ j.jacc.2017.07.758

79. Leung M, van Rosendael PJ, Abou R, Ajmone Marsan N, Leung DY, Delgado $\mathrm{V}$, et al. Left atrial function to identify patients with atrial fibrillation at high risk of stroke: new insights from a large registry. Eur Heart J. (2018) 39:1416-25. doi: 10.1093/eurheartj/ehx736

80. Shih JY, Tsai WC, Huang YY, Liu YW, Lin CC, Huang YS, et al. Association of decreased left atrial strain and strain rate with stroke in chronic atrial fibrillation. J Am Soc Echocardiogr. (2011) 24:513-9. doi: 10.1016/j.echo.2011.01.016

81. Azemi T, Rabdiya VM, Ayirala SR, McCullough LD, Silverman DI. Left atrial strain is reduced in patients with atrial fibrillation, stroke or TIA, and low risk CHADS(2) scores. J Am Soc Echocardiogr. (2012) 25:1327-32. doi: 10.1016/j.echo.2012.09.004

82. Obokata M, Negishi K, Kurosawa K, Tateno R, Tange S, Arai M, et al. Left atrial strain provides incremental value for embolism risk stratification over $\mathrm{CHA}_{2} \mathrm{DS}_{2}$-VASc score and indicates prognostic impact in patients with atrial fibrillation. J Am Soc Echocardiogr. (2014) 27:709-16.e704. doi: 10.1016/j.echo.2014.03.010

83. Proietti M, Marra AM, Tassone EJ, De Vuono S, Corrao S, Gobbi P, et al. Frequency of left ventricular hypertrophy in non-valvular atrial fibrillation. Am J Cardiol. (2015) 116:877-82. doi: 10.1016/j.amjcard.2015.05.060

84. Tezuka Y, Iguchi M, Hamatani Y, Ogawa H, Esato M, Tsuji H, et al. Association of relative wall thickness of left ventricle with incidence of thromboembolism in patients with non-valvular atrial fibrillation: The
Fushimi AF Registry. Eur Heart J Qual Care Clin Outcomes. (2020) 6:273-83. doi: 10.1093/ehjqcco/qcaa003

85. The Stroke Prevention in Atrial Fibrillation Investigators. Predictors of thromboembolism in atrial fibrillation: II. Echocardiographic features of patients at risk. Ann Intern Med. (1992) 116:6-12. doi: 10.7326/0003-4819-116-1-6

86. Atrial Fibrillation Investigators. Echocardiographic predictors of stroke in patients with atrial fibrillation: a prospective study of 1066 patients from 3 clinical trials. Arch Intern Med. (1998) 158:1316-20. doi: 10.1001/archinte.158.12.1316

87. Lee SH, Choi S, Chung WJ, Byun YS, Ryu SK, Pyun WB, et al. Tissue Doppler index, E/E', and ischemic stroke in patients with atrial fibrillation and preserved left ventricular ejection fraction. J Neurol Sci. (2008) 271:148-52. doi: 10.1016/j.jns.2008.04.006

88. Cosansu K, Yilmaz S. Is epicardial fat thickness associated with acute ischemic stroke in patients with atrial fibrillation? J Stroke Cerebrovasc Dis. (2020) 29:104900. doi: 10.1016/j.jstrokecerebrovasdis.2020.104900

89. Black IW. Spontaneous echo contrast: where there's smoke there's fire. Echocardiography. (2000) 17:373-82. doi: 10.1111/j.1540-8175.2000.tb01153.x

90. Zhao Y, Ji L, Liu J, Wu J, Wang Y, Shen S, et al. Intensity of left atrial spontaneous echo contrast as a correlate for stroke risk stratification in patients with nonvalvular atrial fibrillation. Sci Rep. (2016) 6:27650. doi: $10.1038 /$ srep 27650

91. Altinbas K, Guloksuz S, Caglar IM, Caglar FN, Kurt E, Oral ET. Electrocardiography changes in bipolar patients during long-term lithium monotherapy. Gen Hosp Psychiatry. (2014) 36:694-697. doi: 10.1016/j.genhosppsych.2014.07.001

92. He J, Tse G, Korantzopoulos P, Letsas KP, Ali-Hasan-Al-Saegh $\mathrm{S}$, Kamel H, et al. P-wave indices and risk of ischemic stroke: a systematic review and meta-analysis. Stroke. (2017) 48:2066-72. doi: 10.1161/STROKEAHA.117.017293

93. Lacalzada-Almeida J, Izquierdo-Gómez MM, García-Niebla J, Elosua R, Jiménez-Sosa A, Baranchuk A, et al. Advanced interatrial block is a surrogate for left atrial strain reduction which predicts atrial fibrillation and stroke. Ann Noninvasive Electrocardiol. (2019) 24:e12632. doi: 10.1111/anec.12632

94. Mendieta G, Guasch E, Weir D, Aristizabal D, Escobar-Robledo LA, Llull L, et al. Advanced interatrial block: a predictor of covert atrial fibrillation in embolic stroke of undetermined source. J Electrocardiol. (2020) 58:113-18. doi: 10.1016/j.jelectrocard.2019.11.050

95. Donal E, Lip GY, Galderisi M, Goette A, Shah D, Marwan M, et al. EACVI/EHRA Expert Consensus Document on the role of multi-modality imaging for the evaluation of patients with atrial fibrillation. Eur Heart J Cardiovasc Imaging. (2016) 17:355-83. doi: 10.1093/ehjci/jev354

96. Shang L, Zhao Y, Shao M, Sun H, Feng M, Li Y, et al. The association of CHA2DS2-VASc score and carotid plaque in patients with non-valvular atrial fibrillation. PLoS ONE. (2019) 14:e0210945. doi: 10.1371/journal.pone.0210945

97. Wang Z, Korantzopoulos P, Liu T. Carotid atherosclerosis in patients with atrial fibrillation. Curr Atheroscler Rep. (2019) 21:55. doi: 10.1007/s11883-019-0808-4

98. Basili S, Loffredo L, Pastori D, Proietti M, Farcomeni A, Vestri AR, et al. Carotid plaque detection improves the predictive value of CHA(2)DS(2)VASc score in patients with non-valvular atrial fibrillation: the ARAPACIS Study. Int J Cardiol. (2017) 231:143-9. doi: 10.1016/j.ijcard.2017.01.001

99. Cho DH, Choi JI, Choi J, Kim YG, Oh SK, Kook H, et al. Impact of carotid atherosclerosis in CHA2DS2-VASc-based risk score on predicting ischemic stroke in patients with atrial fibrillation. Korean J Intern Med. (2021) 36:342-51. doi: 10.3904/kjim.2019.099

100. Bekwelem W, Jensen PN, Norby FL, Soliman EZ, Agarwal SK, Lip $\mathrm{GY}$, et al. Carotid atherosclerosis and stroke in atrial fibrillation: the atherosclerosis risk in communities study. Stroke. (2016) 47:1643-6. doi: 10.1161/STROKEAHA.116.013133

101. Shang LX, Shao MJ, Zhao Y, Feng M, Sun HX, Jiasuoer X, et al. [The association between carotid atherosclerosis and ischemic stroke in patients with nonvalvular atrial fibrillation]. Zhonghua Nei Ke Za Zhi. (2020) 59:292-6. doi: 10.3760/cma.j.cn112138-20190425-00324

102. Noubiap JJ, Kamtchum-Tatuene J, Fitzgerald JL, Sanders P. Stroke risk associated with carotid and aortic atherosclerosis in patients with atrial fibrillation: a systematic review. 
$J \quad$ Neurol Sci. (2021) $\quad 425: 117444 . \quad$ doi: $\quad 10.1016 / j . j n s .2021 .1$ 17444

103. Perri L, Pastori D, Pignatelli P, Violi F, Loffredo L. Flow-mediated dilation is associated with cardiovascular events in non-valvular atrial fibrillation patients. Int J Cardiol. (2015) 179:139-43. doi: 10.1016/j.ijcard.2014.10.039

104. Eun MY, Jung JM, Choi KH, Seo WK. Statin effects in atrial fibrillationrelated stroke: a systematic review and meta-analysis. Front Neurol. (2020) 11:589684. doi: 10.3389/fneur.2020.589684

105. Wang XY, Zhang F, Zhang C, Zheng LR, Yang J. The biomarkers for acute myocardial infarction and heart failure. BioMed Res Int. (2020) 2020:2018035. doi: 10.1155/2020/2018035

106. Cao Z, Jia Y, Zhu B. BNP and NT-proBNP as diagnostic biomarkers for cardiac dysfunction in both clinical and forensic medicine. Int J Mol Sci. (2019) 20:1820. doi: 10.3390/ijms20081820

107. Sadanaga T, Kohsaka S, Mitamura H, Ogawa S. Elevated B-type natriuretic peptide level as a marker of subsequent thromboembolic events in patients with atrial fibrillation. Heart Vessels. (2011) 26:530-35. doi: 10.1007/s00380-010-0084-2

108. Shibazaki K, Kimura K, Okada Y, Iguchi Y, Terasawa Y, Aoki J. Heart failure may be associated with the onset of ischemic stroke with atrial fibrillation: a brain natriuretic peptide study. J Neurol Sci. (2009) 281:55-7. doi: 10.1016/j.jns.2009.02.374

109. Shimizu H, Murakami Y, Inoue S, Ohta Y, Nakamura K, Katoh H, et al. High plasma brain natriuretic polypeptide level as a marker of risk for thromboembolism in patients with nonvalvular atrial fibrillation. Stroke. (2002) 33:1005-10. doi: 10.1161/hs0402.105657

110. Hijazi Z, Wallentin L, Siegbahn A, Andersson U, Christersson C, Ezekowitz J, et al. N-terminal pro-B-type natriuretic peptide for risk assessment in patients with atrial fibrillation: insights from the ARISTOTLE Trial (Apixaban for the Prevention of Stroke in Subjects With Atrial Fibrillation). J Am Coll Cardiol. (2013) 61:2274-84. doi: 10.1016/j.jacc.2012.11.082

111. Hijazi Z, Oldgren J, Andersson U, Connolly SJ, Ezekowitz MD, Hohnloser $\mathrm{SH}$, et al. Cardiac biomarkers are associated with an increased risk of stroke and death in patients with atrial fibrillation: a Randomized Evaluation of Long-term Anticoagulation Therapy (RE-LY) substudy. Circulation. (2012) 125:1605-16. doi: 10.1161/CIRCULATIONAHA.111.038729

112. Ruff CT, Giugliano RP, Braunwald E, Murphy SA, Brown K, Jarolim P, et al. Cardiovascular biomarker score and clinical outcomes in patients with atrial fibrillation: a subanalysis of the ENGAGE AF-TIMI 48 randomized clinical trial. JAMA Cardiol. (2016) 1:999-1006. doi: 10.1001/jamacardio.2016.3311

113. Roldán V, Vílchez JA, Manzano-Fernández S, Jover E, Gálvez J, Puche $\mathrm{CM}$, et al. Usefulness of N-terminal pro-B-type natriuretic Peptide levels for stroke risk prediction in anticoagulated patients with atrial fibrillation. Stroke. (2014) 45:696-701. doi: 10.1161/STROKEAHA.113.003338

114. Hayashi K, Tsuda T, Nomura A, Fujino N, Nohara A, Sakata K, et al. Impact of B-type natriuretic peptide level on risk stratification of thromboembolism and death in patients with nonvalvular atrial fibrillation- The Hokuriku-Plus AF registry. Circ J. (2018) 82:1271-8. doi: 10.1253/circj.CJ-17-1085

115. Paulin BK, Cedric KK, Tamomh AG, Hui YD. Assessment of cardiac biomarkers (troponin, B-type natriuretic peptide, and D-dimer) in patients with non-valvular atrial fibrillation and stroke. Int J Health Sci. (2019) 13:3-12.

116. Hamatani Y, Iguchi M, Ueno K, Aono Y, Esato M, Tsuji H, et al. Prognostic significance of natriuretic peptide levels in atrial fibrillation without heart failure. Heart. (2020) 107:705-12. doi: 10.1136/heartjnl-2020-317735

117. Shibazaki K, Kimura K, Aoki J, Sakai K, Saji N, Uemura J. Brain natriuretic peptide level on admission predicts recurrent stroke after discharge in stroke survivors with atrial fibrillation. Clin Neurol Neurosurg. (2014) 127:25-9. doi: 10.1016/j.clineuro.2014.09.028

118. Sakamoto Y, Nito C, Nishiyama Y, Suda S, Matsumoto N, Aoki J, et al. Accurate etiology diagnosis in patients with stroke and atrial fibrillation: a role for brain natriuretic peptide. J Neurol Sci. (2019) 400:153-7. doi: 10.1016/j.jns.2019.03.031

119. Tanaka S, Hirai $T$, Inao $K$, Fukuda $N$, Nakagawa $K$, Inoue $H$, et al. High cardiac troponin $\mathrm{I}$ is associated with transesophageal echocardiographic risk of thromboembolism and ischemic stroke events in non-valvular atrial fibrillation patients. Circ J. (2018) 82:1699-704. doi: $10.1253 /$ circj.CJ-17-1238
120. Hijazi Z, Wallentin L, Siegbahn A, Andersson U, Alexander JH, Atar D, et al. High-sensitivity troponin $\mathrm{T}$ and risk stratification in patients with atrial fibrillation during treatment with apixaban or warfarin. J Am Coll Cardiol. (2014) 63:52-61. doi: 10.1016/j.jacc.2013.07.093

121. Roldán V, Marín F, Díaz J, Gallego P, Jover E, Romera M, et al. High sensitivity cardiac troponin $\mathrm{T}$ and interleukin- 6 predict adverse cardiovascular events and mortality in anticoagulated patients with atrial fibrillation. $J$ Thromb Haemost. (2012) 10:1500-7. doi: 10.1111/j.1538-7836.2012.04812.x

122. Berg DD, Ruff CT, Jarolim P, Giugliano RP, Nordio F, Lanz HJ, et al. Performance of the $\mathrm{ABC}$ scores for assessing the risk of stroke or systemic embolism and bleeding in patients with atrial fibrillation in ENGAGE AF-TIMI 48. Circulation. (2019) 139:760-71. doi: 10.1161/CIRCULATIONAHA.118.038312

123. Broersen LHA, Stengl H, Nolte CH, Westermann D, Endres M, Siegerink $\mathrm{B}$, et al. Association between high-sensitivity cardiac troponin and risk of stroke in 96702 individuals: a meta-analysis. Stroke. (2020) 51:1085-93. doi: 10.1161/STROKEAHA.119.028323

124. Oyama K, Giugliano RP, Berg DD, Ruff CT, Jarolim P, Tang M, et al. Serial assessment of biomarkers and the risk of stroke or systemic embolism and bleeding in patients with atrial fibrillation in the ENGAGE AF-TIMI 48 trial. Eur Heart J. (2021) 42:1698-706. doi: 10.1093/eurheartj/ehab141

125. Li N, Zhou H, Tang Q. Red blood cell distribution width: a novel predictive indicator for cardiovascular and cerebrovascular diseases. Dis Markers. (2017) 2017:7089493. doi: 10.1155/2017/7089493

126. Liu T, Shao Q, Korantzopoulos P, Miao S, Zhang Z, Xu G, et al. Relation of red blood cell distribution width with CHADS(2) and CHA(2)DS(2)-VASc score in Chinese patients with non-valvular atrial fibrillation. Int J Cardiol. (2017) 228:861-864. doi: 10.1016/j.ijcard.2016.11.255

127. Zhan XZ, Lin WD, Liu FZ, Xue YM, Liao HT, Li X, et al. Predictive value of red cell distribution width on left atrial thrombus or left atrial spontaneous echo contrast in patients with non-valvular atrial fibrillation. $J$ Geriatr Cardiol. (2018) 15:408-12. doi: 10.11909/j.issn.1671-5411.2018.06.007

128. Cha MJ, Lee HS, Kim HM, Jung JH, Choi EK, Oh S. Association between red cell distribution width and thromboembolic events in patients with atrial fibrillation. Eur J Intern Med. (2017) 46:41-6. doi: 10.1016/j.ejim.2017.07.028

129. Saliba W, Barnett-Griness O, Elias M, Rennert G. The association between red cell distribution width and stroke in patients with atrial fibrillation. Am J Med. (2015) 128:192.e111-198. doi: 10.1016/j.amjmed.2014.09.020

130. Uthamalingam S, Patvardhan EA, Subramanian S, Ahmed W, Martin W, Daley $\mathrm{M}$, et al. Utility of the neutrophil to lymphocyte ratio in predicting long-term outcomes in acute decompensated heart failure. Am J Cardiol. (2011) 107:433-438. doi: 10.1016/j.amjcard.2010.09.039

131. Cosansu K, Vatan MB, Gunduz H, Akdemir R. Use of neutrophil-lymphocyte ratio for risk stratification and relationship with time in therapeutic range in patients with nonvalvular atrial fibrillation: a pilot study. Clin Cardiol. (2018) 41:339-42. doi: 10.1002/clc.22869

132. Ertaş G, Sönmez O, Turfan M, Kul S, Erdogan E, Tasal A, et al. Neutrophil/lymphocyte ratio is associated with thromboembolic stroke in patients with non-valvular atrial fibrillation. J Neurol Sci. (2013) 324:49-52. doi: 10.1016/j.jns.2012.09.032

133. Saliba W, Barnett-Griness O, Elias M, Rennert G. Neutrophil to lymphocyte ratio and risk of a first episode of stroke in patients with atrial fibrillation: a cohort study. J Thromb Haemost. (2015) 13:1971-9. doi: 10.1111/jth. 13006

134. Korniluk A, Koper-Lenkiewicz OM, Kamińska J, Kemona H, DymickaPiekarska V. Mean Platelet Volume (MPV): new perspectives for an old marker in the course and prognosis of inflammatory conditions. Mediators Inflamm. (2019) 2019:9213074. doi: 10.1155/2019/9213074

135. Ha SI, Choi DH, Ki YJ, Yang JS, Park G, Chung JW, et al. Stroke prediction using mean platelet volume in patients with atrial fibrillation. Platelets. (2011) 22:408-14. doi: 10.3109/09537104.2011.560306

136. Choi SW, Kim BB, Choi DH, Park G, Shin BC, Song H, et al. Stroke or left atrial thrombus prediction using antithrombin III and mean platelet volume in patients with nonvalvular atrial fibrillation. Clin Cardiol. (2017) 40:1013-9. doi: 10.1002/clc.22759

137. Gul SS, Gozke E. Mean platelet volume in patients with acute ischemic stroke with nonvalvular atrial fibrillation. Clin Lab. (2018) 64:1909-15. doi: 10.7754/Clin.Lab.2018.180543 
138. Zheng M, Chen S, Zhu Y, Gu X. Mean platelet volume: a new predictor of ischaemic stroke risk in patients with nonvalvular atrial fibrillation. BMC Cardiovasc Disord. (2020) 20:241. doi: 10.1186/s12872-020-01525-x

139. Carroll BJ, Piazza G. Hypercoagulable states in arterial and venous thrombosis: when, how, and who to test? Vasc Med. (2018) 23:388-99. doi: $10.1177 / 1358863 X 18755927$

140. Tripodi A. D-dimer testing in laboratory practice. Clin Chem. (2011) 57:1256-62. doi: 10.1373/clinchem.2011.166249

141. Kim TW, Song IU, Chung SW, Kim JS, Koo J, Lee KS. Serum D-dimer levels are proportionally associated with left atrial enlargement in patients with an acute ischemic stroke due to non-valvular atrial fibrillation. Intern Med. (2016) 55:1447-52. doi: 10.2169/internalmedicine.55.6087

142. Christersson C, Wallentin L, Andersson U, Alexander JH, Ansell J, De Caterina R, et al. D-dimer and risk of thromboembolic and bleeding events in patients with atrial fibrillation-observations from the ARISTOTLE trial. $J$ Thromb Haemost. (2014) 12:1401-12. doi: 10.1111/jth.12638

143. Siegbahn A, Oldgren J, Andersson U, Ezekowitz MD, Reilly PA, Connolly SJ, et al. D-dimer and factor VIIa in atrial fibrillation prognostic values for cardiovascular events and effects of anticoagulation therapy. A RE-LY substudy. Thromb Haemost. (2016) 115:921-30. doi: 10.1055/s-0037-1615530

144. Nozawa T, Inoue H, Hirai T, Iwasa A, Okumura K, Lee JD, et al. D-dimer level influences thromboembolic events in patients with atrial fibrillation. Int J Cardiol. (2006) 109:59-65. doi: 10.1016/j.ijcard.2005.05.049

145. Mahé I, Bergmann JF, Chassany O, dit-Sollier CB, Simoneau G, Drouet L. A multicentric prospective study in usual care: D-dimer and cardiovascular events in patients with atrial fibrillation. Thromb Res. (2012) 129:693-9. doi: 10.1016/j.thromres.2011.08.014

146. Maruyama K, Uchiyama S, Shiga T, Iijima M, Ishizuka K, Hoshino T, et al. Brain natriuretic peptide is a powerful predictor of outcome in stroke patients with atrial fibrillation. Cerebrovasc Dis Extra. (2017) 7:35-43. doi: 10.1159/000457808

147. You LR, Tang M. The association of high D-dimer level with high risk of ischemic stroke in nonvalvular atrial fibrillation patients: a retrospective study. Medicine. (2018) 97:e12622. doi: 10.1097/MD.0000000000012622

148. Sadler JE. Biochemistry and genetics of von Willebrand factor. Annu Rev Biochem. (1998) 67:395-424. doi: 10.1146/annurev.biochem.67.1.395

149. Lip GY, Lowe GD, Rumley A, Dunn FG. Increased markers of thrombogenesis in chronic atrial fibrillation: effects of warfarin treatment. Br Heart J. (1995) 73:527-33. doi: 10.1136/hrt.73.6.527

150. Conway DS, Pearce LA, Chin BS, Hart RG, Lip GY. Plasma von Willebrand factor and soluble p-selectin as indices of endothelial damage and platelet activation in 1321 patients with nonvalvular atrial fibrillation: relationship to stroke risk factors. Circulation. (2002) 106:19627. doi: 10.1161/01.CIR.0000033220.97592.9A

151. Conway DS, Pearce LA, Chin BS, Hart RG, Lip GY. Prognostic value of plasma von Willebrand factor and soluble P-selectin as indices of endothelial damage and platelet activation in 994 patients with nonvalvular atrial fibrillation. Circulation. (2003) 107:3141-5. doi: 10.1161/01.CIR.0000077912.12202.FC

152. Pinto A, Tuttolomondo A, Casuccio A, Di Raimondo D, Di Sciacca R, Arnao $\mathrm{V}$, et al. Immuno-inflammatory predictors of stroke at follow-up in patients with chronic non-valvular atrial fibrillation (NVAF). Clin Sci. (2009) 116:781-9. doi: 10.1042/CS20080372

153. Ancedy Y, Berthelot E, Lang S, Ederhy S, Boyer-Chatenet L, Di Angelantonio $\mathrm{E}$, et al. Is von Willebrand factor associated with stroke and death at midterm in patients with non-valvular atrial fibrillation? Arch Cardiovasc Dis. (2018) 111:357-69. doi: 10.1016/j.acvd.2017.08.004

154. Weymann A, Sabashnikov A, Ali-Hasan-Al-Saegh S, Popov AF, Jalil Mirhosseini S, Baker WL, et al. Predictive role of coagulation, fibrinolytic, and endothelial markers in patients with atrial fibrillation, stroke, and thromboembolism: a meta-analysis, meta-regression, systematic review. Med Sci Monit Basic Res. (2017) 23:97-140. doi: 10.12659/MSMBR.902557

155. Semczuk-Kaczmarek K, Płatek AE, Ry,ś A, Adamowicz J, Legosz P, Kotkowski M, et al. CHA2DS2-VASc score and fibrinogen concentration in patients with atrial fibrillation. Adv Clin Exp Med. (2019) 28:1451-7. doi: 10.17219/acem/104557
156. Di Lecce VN, Loffredo L, Fimognari FL, Cangemi R, Violi F. Fibrinogen as predictor of ischemic stroke in patients with non-valvular atrial fibrillation. $J$ Thromb Haemost. (2003) 1:2453-5. doi: 10.1046/j.1538-7836.2003.0468d.x

157. Wei CC, Zhang ST, Liu JF, Lin J, Yang TT, Zhang SH, et al. Association between fibrinogen and leukoaraiosis in patients with ischemic stroke and atrial fibrillation. J Stroke Cerebrovasc Dis. (2017) 26:2630-7. doi: 10.1016/j.jstrokecerebrovasdis.2017.06.027

158. Qi Z, Chen H, Wen Z, Yuan F, Ni H, Gao W, et al. Relation of low-density lipoprotein cholesterol to ischemic stroke in patients with nonvalvular atrial fibrillation. Am J Cardiol. (2017) 119:1224-8. doi: 10.1016/j.amjcard.2016.12.031

159. Omelchenko A, Hornik-Lurie T, Gabay H, Minha S, Assali A, Pereg D. LDL cholesterol and ischemic stroke in patients with nonvalvular atrial fibrillation. Am J Med. (2020) 134:507-13. doi: 10.1016/j.amjmed.2020.08.035

160. Flint AC, Conell C, Ren X, Kamel H, Chan SL, Rao VA, et al. Statin adherence is associated with reduced recurrent stroke risk in patients with or without atrial fibrillation. Stroke. (2017) 48:1788-94. doi: 10.1161/STROKEAHA.117.017343

161. Zhang Y, Tuomilehto J, Jousilahti P, Wang Y, Antikainen R, Hu G. Total and high-density lipoprotein cholesterol and stroke risk. Stroke. (2012) 43:1768-74. doi: 10.1161/STROKEAHA.111.646778

162. Zhang XX, Wei M, Shang LX, Lu YM, Zhang L, Li YD, et al. LDL $\mathrm{C} / \mathrm{HDL}-\mathrm{C}$ is associated with ischaemic stroke in patients with non-valvular atrial fibrillation: a case-control study. Lipids Health Dis. (2020) 19:217. doi: 10.1186/s12944-020-01392-7

163. Okura $\mathrm{H}$, Inoue $\mathrm{H}$, Tomon $\mathrm{M}$, Nishiyama $\mathrm{S}$, Yoshikawa $\mathrm{T}$. Increased plasma lipoprotein(a) level in cardioembolic stroke with non-valvular atrial fibrillation. Intern Med. (1998) 37:995. doi: 10.2169/internalmedicine.37.995

164. Aronis KN, Zhao D, Hoogeveen RC, Alonso A, Ballantyne CM, Guallar E, et al. Associations of lipoprotein(a) Levels with incident atrial fibrillation and ischemic stroke: the ARIC (Atherosclerosis Risk in Communities) study. $J$ Am Heart Assoc. (2017) 6:pii: e007372. doi: 10.1161/JAHA.117.007372

165. da Silva RM. Influence of inflammation and atherosclerosis in atrial fibrillation. Curr Atheroscler Rep. (2017) 19:2. doi: 10.1007/s11883-017-0639-0

166. Dernellis J, Panaretou M. Left atrial function in patients with a high Creactive protein level and paroxysmal atrial fibrillation. Acta Cardiol. (2006) 61:507-11. doi: 10.2143/AC.61.5.2017764

167. Lip GY, Patel JV, Hughes E, Hart RG. High-sensitivity C-reactive protein and soluble CD40 ligand as indices of inflammation and platelet activation in 880 patients with nonvalvular atrial fibrillation: relationship to stroke risk factors, stroke risk stratification schema, and prognosis. Stroke. (2007) 38:1229-37. doi: 10.1161/01.STR.0000260090.90508.3e

168. Aulin J, Siegbahn A, Hijazi Z, Ezekowitz MD, Andersson U, Connolly SJ, et al. Interleukin-6 and C-reactive protein and risk for death and cardiovascular events in patients with atrial fibrillation. Am Heart J. (2015) 170:1151-60. doi: 10.1016/j.ahj.2015.09.018

169. Zhang J, Zheng R, Li H, Guo J. Serum uric acid and incident atrial fibrillation: a systematic review and dose-response meta-analysis. Clin Exp Pharmacol Physiol. (2020) 47:1774-82. doi: 10.1111/1440-1681.13374

170. Tang RB, Dong JZ, Yan XL, Du X, Kang JP, Wu JH, et al. Serum uric acid and risk of left atrial thrombus in patients with nonvalvular atrial fibrillation. Can J Cardiol. (2014) 30:1415-21. doi: 10.1016/j.cjca.2014.06.009

171. Ning W, Li Y, Ma C, Qiu L, Yu B. The refinement of risk stratification for atrial thrombus or spontaneous echo contrast in nonvalvular atrial fibrillation. Int Heart J. (2017) 58:885-93. doi: 10.1536/ihj.16-444

172. Liu FZ, Liao HT, Lin WD, Xue YM, Zhan XZ, Fang XH, et al. Predictive effect of hyperuricemia on left atrial stasis in non-valvular atrial fibrillation patients. Int J Cardiol. (2018) 258:103-8. doi: 10.1016/j.ijcard.2018.01.080

173. Song Z, Xu K, Hu X, Jiang W, Wu S, Qin M, et al. A study of cardiogenic stroke risk in non-valvular atrial fibrillation patients. Front Cardiovasc Med. (2020) 7:604795. doi: 10.3389/fcvm.2020.604795

174. Numa S, Hirai T, Nakagawa K, Ohara K, Fukuda N, Nozawa T, et al. Hyperuricemia and transesophageal echocardiographic thromboembolic risk in patients with atrial fibrillation at clinically low-intermediate risk. Circ J. (2014) 78:1600-5. doi: 10.1253/circj.CJ-13-1385 
175. Chao TF, Liu CJ, Chen SJ, Wang KL, Lin YJ, Chang SL, et al. Hyperuricemia and the risk of ischemic stroke in patients with atrial fibrillation-could it refine clinical risk stratification in AF? Int J Cardiol. (2014) 170:344-9. doi: 10.1016/j.ijcard.2013.11.011

176. Tarnowski D, Poitz DM, Plichta L, Heidrich FM, Wiedemann S, Ruf $\mathrm{T}$, et al. Comparison of diverse platelet activation markers as indicators for left atrial thrombus in atrial fibrillation. Platelets. (2018) 29:41-7. doi: 10.1080/09537104.2017.1293805

177. Duygu H, Barisik V, Kurt H, Turk U, Ercan E, Kose S. Prognostic value of plasma soluble CD40 ligand in patients with chronic non-valvular atrial fibrillation. Europace. (2008) 10:210-4. doi: 10.1093/europace/eum284

178. Ferro D, Loffredo L, Polimeni L, Fimognari F, Villari P, Pignatelli P, et al. Soluble CD40 ligand predicts ischemic stroke and myocardial infarction in patients with nonvalvular atrial fibrillation. Arterioscler Thromb Vasc Biol. (2007) 27:2763-8. doi: 10.1161/ATVBAHA.107.152777

179. Ay H, Arsava EM, Tokgözoglu SL, Ozer N, Saribas O. Hyperhomocysteinemia is associated with the presence of left atrial thrombus in stroke patients with nonvalvular atrial fibrillation. Stroke. (2003) 34:909-12. doi: 10.1161/01.STR.0000060202.63475.BA

180. Loffredo L, Violi F, Fimognari FL, Cangemi R, Sbrighi PS, Sampietro $\mathrm{F}$, et al. The association between hyperhomocysteinemia and ischemic stroke in patients with non-valvular atrial fibrillation. Haematologica. (2005) 90:1205-11.

181. Yao Y, Gao LJ, Zhou Y, Zhao JH, Lv Q, Dong JZ, et al. Effect of advanced age on plasma homocysteine levels and its association with ischemic stroke in non-valvular atrial fibrillation. J Geriatr Cardiol. (2017) 14:743-9. doi: 10.11909/j.issn.1671-5411.2017.12.004

182. Blessberger H, Mueller P, Makimoto H, Hauffe F, Meissner A, Gemein C, et al. Association of adipocytokines serum levels with left atrial thrombus formation in atrial fibrillation patients on oral anticoagulation (Alert) - a cross-sectional study. Nutr Metab Cardiovasc Dis. (2021) 31:860-8. doi: 10.1016/j.numecd.2020.11.007

183. Carnevale R, Pastori D, Peruzzi M, De Falco E, Chimenti I, Biondi-Zoccai G, et al. Total adiponectin is inversely associated with platelet activation and $\mathrm{CHA}_{2} \mathrm{DS}_{2}$-VASc score in anticoagulated patients with atrial fibrillation. Mediators Inflamm. (2014) 2014:908901. doi: 10.1155/2014/908901

184. Hernández-Romero D, Jover E, Marín F, Vilchez JA, Manzano-Fernandez $\mathrm{S}$, Romera $\mathrm{M}$, et al. The prognostic role of the adiponectin levels in atrial fibrillation. Eur J Clin Invest. (2013) 43:168-73. doi: 10.1111/eci.12028

185. Assadi A, Zahabi A, Hart RA. GDF15, an update of the physiological and pathological roles it plays: a review. Pflugers Arch. (2020) 472:1535-46. doi: 10.1007/s00424-020-02459-1

186. Hu XF, Zhan R, Xu S, Wang J, Wu J, Liu X, et al. Growth differentiation factor 15 is associated with left atrial/left atrial appendage thrombus in patients with nonvalvular atrial fibrillation. Clin Cardiol. (2018) 41:34-8. doi: $10.1002 /$ clc. 22844

187. Wallentin L, Hijazi Z, Andersson U, Alexander JH, De Caterina R, Hanna $\mathrm{M}$, et al. Growth differentiation factor 15, a marker of oxidative stress and inflammation, for risk assessment in patients with atrial fibrillation: insights from the Apixaban for Reduction in Stroke and Other Thromboembolic Events in Atrial Fibrillation (ARISTOTLE) trial. Circulation. (2014) 130:1847-58. doi: 10.1161/CIRCULATIONAHA.114.011204

188. Liang Z, Dong Z, Guo M, Shen Z, Yin D, Hu S, et al. Trimethylamine Noxide as a risk marker for ischemic stroke in patients with atrial fibrillation. $J$ Biochem Mol Toxicol. (2019) 33:e22246. doi: 10.1002/jbt.22246

189. Yuan S, Lin A, He QQ, Burgess S, Larsson SC. Circulating interleukins in relation to coronary artery disease, atrial fibrillation and ischemic stroke and its subtypes: a two-sample Mendelian randomization study. Int J Cardiol. (2020) 313:99-104. doi: 10.1016/j.ijcard.2020.03.053

190. Wu N, Chen X, Cai T, Wu L, Xiang Y, Zhang M, et al. Association of inflammatory and hemostatic markers with stroke and thromboembolic events in atrial fibrillation: a systematic review and meta-analysis. Can J Cardiol. (2015) 31:278-86. doi: 10.1016/j.cjca.2014.12.002

191. Tang Z, Zeng L, Lin Y, Han Z, Gu J, Wang C, et al. Circulating Galectin-3 is associated with left atrial appendage remodelling and thrombus formation in patients with atrial fibrillation. Heart Lung Circ. (2019) 28:923-31. doi: 10.1016/j.hlc.2018.05.094
192. Begg GA, Karim R, Oesterlein T, Graham LN, Hogarth AJ, Page SP, et al. Left atrial voltage, circulating biomarkers of fibrosis, and atrial fibrillation ablation. A prospective cohort study. PLoS ONE. (2018) 13:e0189936. doi: 10.1371/journal.pone.0189936

193. Roselli C, Rienstra M, Ellinor PT. Genetics of atrial fibrillation in 2020: GWAS. genome sequencing, polygenic risk, and beyond. Circ Res. (2020) 127:21-33. doi: 10.1161/CIRCRESAHA.120.316575

194. Tada H, Shiffman D, Smith JG, Sjögren M, Lubitz SA, Ellinor PT, et al. Twelve-single nucleotide polymorphism genetic risk score identifies individuals at increased risk for future atrial fibrillation and stroke. Stroke. (2014) 45:2856-62. doi: 10.1161/STROKEAHA.114.006072

195. Pulit SL, Weng LC, McArdle PF, Trinquart L, Choi SH, Mitchell $\mathrm{BD}$, et al. Atrial fibrillation genetic risk differentiates cardioembolic stroke from other stroke subtypes. Neurol Genet. (2018) 4:e293. doi: 10.1212/NXG.0000000000000293

196. Cruz D, Pinto R, Freitas-Silva M, Nunes JP, Medeiros R. GWAS contribution to atrial fibrillation and atrial fibrillation-related stroke: pathophysiological implications. Pharmacogenomics. (2019) 20:765-780. doi: 10.2217/pgs-2019-0054

197. Hsieh CS, Huang PS, Chang SN, Wu CK, Hwang JJ, Chuang EY, et al. Genome-Wide copy number variation association study of atrial fibrillation related thromboembolic stroke. J Clin Med. (2019) 8:332. doi: $10.3390 /$ jcm 8030332

198. O'Sullivan JW, Shcherbina A, Justesen JM, Turakhia M, Perez M, Wand $\mathrm{H}$, et al. Combining clinical and polygenic risk improves stroke prediction among individuals with atrial fibrillation. Circ Genom Precis Med. (2021) 14:e003168. doi: 10.1161/CIRCGEN.120.003168

199. Zou R, Zhang D, Lv L, Shi W, Song Z, Yi B, et al. Bioinformatic gene analysis for potential biomarkers and therapeutic targets of atrial fibrillation-related stroke. J Transl Med. (2019) 17:45. doi: 10.1186/s12967-019-1790-x

200. Zhang YF, Meng LB, Hao ML, Yang JF, Zou T. Identification of co-expressed genes between atrial fibrillation and stroke. Front Neurol. (2020) 11:184. doi: 10.3389/fneur.2020.00184

201. Kiyosawa N, Watanabe K, Morishima Y, Yamashita T, Yagi N, Arita T, et al. Exploratory analysis of circulating mirna signatures in atrial fibrillation patients determining potential biomarkers to support decision-making in anticoagulation and catheter ablation. Int J Mol Sci. (2020) 21:2444. doi: $10.3390 /$ ijms 21072444

202. Zeng $\mathrm{W}$, Jin J. The correlation of serum long non-coding RNA ANRIL with risk factors, functional outcome, and prognosis in atrial fibrillation patients with ischemic stroke. J Clin Lab Anal. (2020) 34:e23352. doi: $10.1002 /$ jcla. 23352

203. Hijazi Z, Wallentin L, Lindbäck J, Alexander JH, Connolly SJ, Eikelboom JW, et al. Screening of multiple biomarkers associated with ischemic stroke in atrial fibrillation. J Am Heart Assoc. (2020) 9:e018984. doi: 10.1161/JAHA.120.018984

204. Roldán V, Rivera-Caravaca JM, Shantsila A, García-Fernández A, EstevePastor MA, Vilchez JA, et al. Enhancing the "real world" prediction of cardiovascular events and major bleeding with the CHA(2)DS(2)-VASc and HAS-BLED scores using multiple biomarkers. Ann Med. (2018) 50:26-34. doi: 10.1080/07853890.2017.1378429

205. Rivera-Caravaca JM, Marín F, Vilchez JA, Gálvez J, Esteve-Pastor MA, Vicente V, et al. Refining stroke and bleeding prediction in atrial fibrillation by adding consecutive biomarkers to clinical risk scores. Stroke. (2019) 50:1372-9. doi: 10.1161/STROKEAHA.118.024305

Conflict of Interest: The authors declare that the research was conducted in the absence of any commercial or financial relationships that could be construed as a potential conflict of interest.

Copyright $(2021$ Shang, Zhang, Guo, Sun, Zhang, Bo, Zhou and Tang. This is an open-access article distributed under the terms of the Creative Commons Attribution License (CC BY). The use, distribution or reproduction in other forums is permitted, provided the original author(s) and the copyright owner(s) are credited and that the original publication in this journal is cited, in accordance with accepted academic practice. No use, distribution or reproduction is permitted which does not comply with these terms. 